\title{
CREANDO UN ESTADO DE BIENESTAR EN UN RÉGIMEN AUTORITARIO: EL CASO DE BRASIL
}

\author{
Herbert S. Klein* \\ Francisco Vidal Luna***
}

\begin{abstract}
Resumen
Este artículo detalla los orígenes y la evolución del sistema de protección social brasileño desde la época del Estado Novo de Getúlio Vargas hasta los regímenes militares de I964 a I985. El caso de Brasil es bastante inusual, ya que el Estado de Bienestar fue creado por gobiernos no democráticos. Este enfoque de arriba hacia abajo respondió a las necesidades del gobierno tanto de satisfacer las demandas de una clase trabajadora moderna en un país de reciente industrialización como de controlar protestas populares y concitar apoyo. A pesar de sus orígenes y su estructura autoritaria, gran parte de este sistema ha sobrevivido en la era post-militar, siendo hoy, con modestos cambios de énfasis, la base del Estado de Bienestar brasileño.
\end{abstract}

Palabras clave: Estado de Bienestar, Brasil, régimen autoritario, Getúlio Vargas, salud, educación

* Professor, Stanford University. Correo electrónico: hklein@stanford.edu. ** Doctor en Economía, Universidade de São Paulo. Correo electrónico: fvluna1@gmail.com. 
Creating a Welfare State in an Authoritarian Regime: The Case of Brazil

\begin{abstract}
This article details the origins and evolution of the Brazilian welfare system from the time of the Estado Novo of Getúlio Vargas through the military regimes of I964-1985. Brazil's case is fairly unusual in that its construction of the welfare state was created by non-democratic governments. This top down approach we argue responded to government needs to provide for a modern working class for a newly industrializing nation and to control popular protest and generate support. Yet for all its authoritarian origins and structure, much of the system which was created has survived into the post-military era, with only modest change of emphasis, and is today the basis for Brazil's social welfare state.
\end{abstract}

Keywords: Welfare state, Brazil, authoritarian regime, Getúlio Vargas, health, education

L

a creación de un Estado de Bienestar en Brasil siguió, a lo largo de su historia, la evolución tradicional latinoamericana hasta la militares con montepíos, recayendo en la Iglesia la responsabilidad de establecer una serie de instituciones de caridad, desde hospitales a orfanatos. Este panorama no cambió mayormente durante el siglo XIX, aun cuando en los últimos días del gobierno imperial se entregaron a algunos empleados gubernamentales pensiones mínimas en los ámbitos de la educación y salud pública. Sin embargo, como la mayoría de los Estados latinoamericanos, hasta la Gran Depresión no se avanzó mayormente en las áreas de bienestar (Abel y Lewis I993; Mesa-Lago I997: Cap. 2).

A pesar de que el nuevo gobierno republicano establecido en i889 puso mayor énfasis en mejorar la salud y la educación, llevando a cabo grandes campañas de vacunación y saneamiento y promoviendo escuelas públicas gratuitas mantenidas por los gobiernos estatales y municipales, no hubo grandes cambios institucionales en salud, regulación de pensiones o propuestas específicas para compensar a los trabajadores. No fue sino hasta I9I9 que se aprobaron las primeras compensaciones 
nacionales a trabajadores accidentados, y tan solo en I923 fue sancionado el primer plan de pensiones apoyado por el gobierno bajo la Ley Eloy Chaves (do Valle 20II: 62). Este plan creó un fondo de pensiones impulsado por el gobierno para los trabajadores ferroviarios a lo largo de la nación, aunque fue pagado por empleadores y empleados. Junto a estas contribuciones, se asignó un nuevo precio a los boletos de ferrocarriles, los cuales serían también aplicados a los fondos de la Caixa de Aposentadorias e Pensões (CAP). En I926, se estableció otra CAP para trabajadores portuarios; lo mismo ocurrió en I928 para trabajadores de telégrafos. El decreto de 1926 extendió los planes a las familias e incluso a los herederos de los pensionistas. Estos derechos incluían servicios médicos y quirúrgicos, pensiones después de treinta años de servicio y cincuenta años de edad, beneficios por fallecimiento y pensiones de invalidez después de diez años de servicio. A su vez, las pensiones se estimaban considerando un promedio de salarios de los últimos cinco años de servicio, en los cuales los trabajadores con menos recursos recibían el 90\% de sus sueldos como pensiones y los más ricos sólo el 60\%. Para i930, existían 47 de este tipo de CAPs, con cerca de 142.000 trabajadores cotizando y con I5.000 beneficiarios. Fue sólo después de la década de I930 que se comenzó a pensar que estos beneficios eran demasiado generosos y que no estaban basados en principios actuariales. Así, dentro de unos años, algunas de estas Caixas se encontrarían ante serias dificultades financieras, con beneficios que excedían sus ingresos (Oliveira y Fleury I986: 20-34, 342).

Las respuestas más bien tímidas por parte de los gobiernos republicanos a la cada vez más dramática 'cuestión social' que emergió en los sectores industriales y urbanos de Brasil incluyeron también algunos intentos de establecer varios institutos del Trabajo y secretarías para hacer frente a las huelgas y a las consideraciones de bien-


Mientras la mayoría de los otros países se movería lentamente hacia sistemas más universales -especialmente después de I945, cuando se llevaron a cabo complejas negociaciones entre los gobiernos democráti-

${ }^{\mathrm{I}}$ Aunque el período más radical de huelgas ocurrió en I9I7-I920, la cuestión social continuó siendo un tema sumamente relevante en todos los debates políticos de la décadas de I9I0 y I920. Para una cronología de la actividad huelguista, véase Giannotti (2007). Los análisis estándar sobre estos movimientos son Fausto (1997) y Batalha (2000). 
camente elegidos, empleadores y trabajadores con el fin de establecer un sistema de bienestar moderno- Brasil no adoptó este camino.

En I930, Getúlio Vargas alcanzó el poder y, a partir de I937, desarrolló un efectivo régimen autoritario a través del llamado Estado Novo. Fueron el régimen autoritario de Vargas, entre I930 y I945, y los gobiernos autoritarios de los militares brasileños entre I964 y I985 los que establecieron la infraestructura básica para la creación en Brasil de un Estado de Bienestar moderno. Aunque dicha infraestructura sería modificada, universalizada, reformada en la Constitución de I988 y sancionada durante el gobierno democrático que remplazó al régimen militar, muchas de sus características esenciales están todavía en operación en la actualidad, cuando el Estado gasta un $42 \%$ de su presupuesto en bienestar social. ${ }^{2}$

De ese modo, el caso de Brasil contrasta con la conocida historia de democracia política y legislación de bienestar. En vez de encontrarnos con administraciones que responden a las demandas de los trabajadores y negocian con empleadores, en Brasil fueron los gobiernos los que anticiparon las demandas e impusieron condiciones tanto sobre trabajadores como empleadores. Se trató de un enfoque de arriba hacia abajo, en el cual los consumidores y contribuyentes no jugaron un papel influyente.

En este artículo intentaremos explicar, por un lado, las razones de este enfoque de arriba hacia abajo adoptado por los regímenes autoritarios de Brasil y, por otro, ilustrar la evolución de las instituciones que formaron la columna vertebral de lo que se transformaría en un Estado de Bienestar moderno impulsado por el gobierno. Fueron principalmente los regímenes autoritarios los que sentaron las bases del acceso universal en salud y educación para todos los ciudadanos, creando a su vez un complejo mercado de pensiones estatales y privadas que aún hoy continúa vigente.

Los orígenes autoritarios del sistema de bienestar están relacionados con las especificidades del gobierno republicano fundado en i889 y con las tendencias ideológicas europeas del período post I9I4. La república brasileña comenzó como un régimen controlado por una pequeña oligarquía, cuya administración descentralizada y federal estaba sustancialmen-

${ }^{2}$ Este es el promedio estimado de los gastos del gobierno central brasileño en programas de seguridad social, salud y educación durante el período I973-2000. Este porcentaje es similar al 45\% y $46 \%$ de Estados Unidos y Canadá, pero es más bajo que el 50-60\% de los países nórdicos. A su vez, representa el I3,5\% del PIB (Segura-Ubiergo 2007: I4-5). 
te en manos de las élites de dos Estados: Minas Gerais y São Paulo. La revolución de I930 liderada por Vargas fue una respuesta a los excesos de este gobierno. Vargas inmediatamente empujó la balanza de poder desde los Estados al gobierno central, tal como había ocurrido durante el Imperio. La oligarquía, además, se vio amenazada por las élites, la cual en I932 lideró una rebelión armada en contra del gobierno de Vargas. En este contexto, el Estado liberal como había sido establecido tanto por la Constitución republicana de 1890 como por aquella inicialmente preparada en I933 bajo el régimen de Vargas, fue progresivamente cuestionado por los líderes políticos que apoyaban a Vargas. No sólo eso: debido a que Vargas en este período fue jefe del gobierno provisional enfrentó la hostilidad de la élite, por lo que fue esencial para él crear nuevas fuentes de poder. Vargas fue el primer líder brasileño en darse cuenta de la fuerza de las clases obreras urbanas. Éstas, en efecto, eran un poder no explotado que recién comenzaba a expresarse a través de huelgas e incipientes movimientos políticos socialistas, comunistas y anarquistas, teniendo suficiente potencial para ser movilizadas en apoyo del régimen.

Por su parte, los intelectuales que apoyaron la revolución de Vargas fueron influenciados por las ideologías antiliberales que alcanzaron reconocimiento en Europa luego de la Primera Guerra Mundial. Dichas ideologías recorrían el espectro desde la hispanidad al corporativismo a través del fascismo y un catolicismo reaccionario que, en las décadas de i920 y I930, habían encontrado una rápida acogida entre un grupo de intelectuales brasileños opositores a las élites liberales que habían gobernado el país durante la República. Aunque sólo algunos se transformarían en fascistas y otros seguirían las ideologías católicas conservadoras, ${ }^{3}$ el grupo más poderoso que emergería de estos cambios promovería una combinación de posturas nacionalistas, autoritarias y racistas. ${ }^{4}$ Siguiendo los modelos

${ }^{3}$ Los intelectuales conservadores católicos apoyaron sus propios movimientos, como también dieron un apoyo tácito a un grupo del partido brasileño fascista conocido como los integralistas (Todaro I974: 43I-52).

${ }^{4}$ Como señaló Boris Fausto en su excelente estudio de estos intelectuales sobre el derecho, es posible encontrar una ideología nacionalista (Fausto 200I: I6-7). De acuerdo con Miceli (I979: I67), la mayoría de estos intelectuales pertenecía a las élites oligárquicas. Además, según este autor, el grupo dominante de escritores modernistas e intelectuales en São Paulo continuó siendo democrático y liberal, sobre todo por el hecho de que Vargas nombró interventores militares en el gobierno estatal, los cuales no pertenecían a las familias oligárquicas del Estado como tampoco estaban vinculados a las élites de los partidos locales (Miceli ı979: Cap. I). 
corporativistas y fascistas, especialmente luego de que el fascismo alcanzara el poder en Italia durante los años I920 y se afianzara ahí durante la década siguiente, 5 este grupo de intelectuales brasileños promovería la idea de un líder carismático como la mejor solución para salir de la 'crisis' que afectaba a la república brasileña.

Durante la década de I920, fermentaron nuevas ideas en Brasil, desde los modernistas en São Paulo hasta los fascistas y conservadores en otros Estados brasileños. Sin embargo, las ideologías antiliberales y antidemocráticas que ejercieron mayor influencia fueron aquellas que el historiador Boris Fausto denominó "autoritarias nacionalistas" (200I: I5). Estas ideologías sostenían que unicamente una respuesta no liberal pondría fin a las tensiones provocadas por la 'cuestión social', esto es, los problemas planteados por el conflicto de clases en la era de la industrialización. Sólo un régimen autoritario sostendría estas ideologías, pondría coto a los excesos del capitalismo, reprimiría a los movimientos de izquierda y generaría armonía. Pero, incluso más importante, creían que un desarrollo coherente hacia una sociedad moderna e industrial sólo podría hacerse realidad mediante un Estado centralizado que fuera dirigido por un Poder Ejecutivo todopoderoso y que no estuviera controlado por las élites locales ni restringido por limitaciones democráticas. Fue esta forma de pensamiento la que dominó el período de Vargas y también el posterior gobierno de los militares en I964. Que algunos de estos intelectuales y sus ideas estuvieron presentes en ambos períodos puede comprobarse estudiando la figura del jurista pro-fascista y proveniente de Minas Gerais Francisco Campos (I89I-I968), uno de los ideólogos más poderosos de esta escuela y quien no sólo participó de la preparación de la Constitución autoritaria de I937 del Estado Novo sino también en la publicación de los decretos fundamentales del régimen militar de I964. Durante el gobierno de Vargas, Campos fue ministro de educación, salud y justicia; posteriormente trabajó muy de cerca con los partidarios civiles de la revuelta militar de i964. A pesar de que la Constitución de I937 preveía un plebiscito, una legislatura e incluso una

${ }^{5}$ Aunque algo tarde para estándares europeos, el Estado liberal italiano había puesto en práctica un programa de bienestar social mucho más extenso que el brasileño con anterioridad a I920. También aprobó un acta de desempleo en I9I9. Fue este régimen de bienestar liberal que el Estado fascista expandió y transformó en una organización supuestamente más moderna, aunque sin un financiamiento directo por parte del Estado y haciendo que la mayoría de los costos fueran pagados por las clases trabajadoras. Véase Quine (2002: Cap. 4), Zamagni (2000: 67I-750). 
supervisión judicial, Vargas gobernó por decreto. Fueron estos decretos los que utilizó Campos para modelar los decretos 'constitucionales' Atos Institucionais (AI) que, más adelante, serían legitimados por los regímenes militares. El preámbulo del primero de estos famosos decretos -que daban poderes ilimitados al Ejecutivo- destacó que su legitimidad provenía del acto revolucionario en sí mismo, el cual, según Campos, era tan válido como el voto popular. ${ }^{6}$

Así, el proceso de creación de instituciones de bienestar sería un desarrollo de arriba hacia abajo y tendría como fin conquistar el apoyo de la clase trabajadora, la cual era vista como un nuevo poder político en Brasil.7 Para los autoritarios nacionalistas ésta también era una forma de alejar a las clases trabajadoras de los partidos y movimientos de izquierda, considerados como ideologías 'exóticas' que ponían trabas a la evolución natural de la población brasileña. ${ }^{8}$ También se creía que las instituciones de bienestar podían ser utilizadas para lo que Vargas denominaba "revigorizar la raza" y, más específicamente, para el "perfeccionamiento eugenésico de la raza” (Vargas I943: 233). Esta era una referencia explícita a las ideas racistas y eugenésicas de moda entre las ideologías autoritarias de la época. ${ }^{9}$ A esta ideología se le unió otra más antigua que consideraba a los militares como los defensores del Estado y como el 'poder moderado' en la política brasileña. Los militares, en efecto, estaban llamados a mantener al país en la senda del desarrollo y a ser la

${ }^{6}$ Todos los autores enfatizan el compromiso de Campos al culto del dictador, su imitación de la Constitución fascista de Polonia durante ese período y finalmente su apoyo declarado tanto a Mussolini como a Hitler y a los Estados fascistas con posterioridad a I945. Al parecer, también fue influenciado por el extraño autoritarismo de la Constitución del Estado de Río Grande do Sul escrita por el gobernador Júlio de Castilhos en I891, como también por el jurista alemán y fascista Carl Schmitt. Fueron estos decretos los que Campos utilizó para diseñar los Atos Institucionais 'constitucionales' escritos para los regímenes militares después de I964. Véase Fernandes (2007: 35I-70), dos Santos (2007: 28I-323), Fausto (200I: 29).

7 De acuerdo con Bello, Vargas cambió la cuestión social desde un tema policial a uno relacionado con la incorporación de la clase trabajadora. Los derechos sociales de ciudadanía fueron incorporados en el sistema judicial brasileño de arriba hacia abajo, pero eran asignados por el gobierno y no conquistados por las clases trabajadoras (como había ocurrido en los países más avanzados de Europa). Esta asignación de derechos llevó a Vargas a ser considerado "el padre del pobre" (Bello 2007: 139).

${ }^{8}$ Fausto enfatiza su constante referencia e ideologías 'exóticas' y, como ellos, pensaba que las soluciones autoritarias eran más ‘brasileñas' que las llamadas 'ideas importadas' (Fausto 200I).

${ }^{9}$ Según Fausto, una característica común de estos nacionalistas autoritarios era la importancia que daban a la denominada cuestión racial (Fausto 2001: 38). Muchos de ellos eran entusiastas seguidores del movimiento eugenésico y casi todos ellos señalaron la necesidad de blanquear a la población brasileña. 
fuerza que frenaría los excesos de la democracia política y el descarrilamiento del proceso de modernización. ${ }^{10}$

La revolución de Vargas, como vemos, tuvo como objetivo principal el ajuste del Estado a las nuevas realidades sociales de una sociedad más compleja. Durante el período de Vargas el Estado comenzó a generar una serie de instituciones básicas para hacer frente a las relaciones laborales, siendo la salud pública, las pensiones y la economía las responsables de mover a los brasileños de una sociedad oligárquica rural a una más moderna. Esto se hizo durante un gobierno no democrático que pudo forjar nuevas alianzas con el emergente sector industrial y aprovechar el movimiento laboral como un apoyo permanente al régimen a cambio de protección a los trabajadores. Su naturaleza autoritaria ayudó a Vargas a reducir el poder de las antiguas oligarquías, impidiéndoles a su vez que se opusieran a los cambios introducidos por su gobierno.

Mientras la Vieja República descansaba en una alianza entre las regiones y la élite cafetera, el nuevo gobierno tenía una estructura más compleja y heterogénea, estando esta última controlada por grupos de militares, tecnócratas y políticos jóvenes. ${ }^{\text {II }}$ Muchos de estos hombres, Vargas incluido, habían sido parte del régimen anterior. ${ }^{\mathrm{I2}}$ Más tarde, los industrialistas fueron incorporados en esta nueva estructura de poder. El antiguo liberalismo fue reemplazado por un régimen autoritario, centralizado y moderno, un cambio que, de hecho, estaba ocurriendo al mismo tiempo en diferentes países latinoamericanos a raíz de la Gran Depresión. De acuerdo con la mayoría de los académicos que trabajan este tema, el nuevo autoritarismo implicó la transición de un Estado oligárquico, afianzado en la élite territorial, hacia una nueva estructura política basada en la creación de compromisos entre grupos en competencia. Sin

Io Esto puede verse claramente en la ideología del General Góes Monteiro, una figura señera del gobierno de Vargas y líder de la revuelta en contra de este mismo en I945 (Fausto 200I: 63-4).

II Los tenientes, quienes tuvieron un papel fundamental en el movimiento armado que derrocó al gobierno establecido, como grupo tuvieron una gran importancia en el liderazgo y administración en los primeros años de los nuevos gobiernos. Pero poco a poco fueron perdiendo fuerza como grupo organizado debido a su radicalismo, su incapacidad para cuestionar al gobierno; o bien fueron absorbidas por los nuevos grupos oligarcas que llegaron al poder. Algunos de los tenientes mantuvieron de forma individual un papel clave a lo largo del período de Vargas (Fausto I972: 70-82).

${ }^{12}$ Vargas ya había sido Ministro de Hacienda en el gobierno de Washington Luís y gobernador del Estado de Río Grande do Sul. Sobre Getulio Vargas véase Bourn (I974), Dulles (I967), Neto (20I2), Zahluth y Dutra (20I2). 
embargo, inicialmente ninguno de los grupos de poder proveyó suficiente legitimidad y compromiso al nuevo Estado: la clase media porque no tenía autonomía política frente a los intereses tradicionales; los intereses cafeteros porque fueron desplazados del poder político; y los participantes del mercado interno porque no estaban vinculados a los principales centros de la economía. En ninguno de estos casos fueron utilizados sus intereses sociales y económicos particulares como la expresión política del interés general.

En palabras del politólogo Francisco Weffort, para Vargas las masas urbanas eran "la única fuente posible de legitimidad del nuevo gobierno brasileño” (Weffort I980: 49-50). El estilo gubernamental inaugurado por Vargas -clasificado por algunos como populismo o sensible a presiones populares y por otros como un régimen de política de masas- buscó liderar al país mediante la manipulación de las aspiraciones populares, las cuales sólo podían ser comprendidas en el contexto de la crisis política y económica provocada por la revolución de 1930. Con el propósito de establecer el apoyo de las clases trabajadoras urbanas que eran nuevas en la política nacional, los gestores de los movimientos reformistas de la década de I930 creían que sólo "un autoritarismo institucional o el autoritarismo paternalista de líderes carismáticos" (Weffort I980: 6I) podía llevar adelante la industrialización y modernización de sus respectivas sociedades. ${ }^{13}$

Al asumir el gobierno, Vargas disolvió las legislaturas nacional, estatal y municipal, y nombró a interventores específicos para remplazar a los gobernadores de los Estados. También dio mayor poder al gobierno federal y redujo el de los Estados. ${ }^{14}$ Después de la aprobación de la nueva

${ }^{13}$ El populismo en Brasil ha sido objeto de innumerables estudios desde los años i960. Recientemente han aparecido estudios sobre el tema, entre ellos Ferreira (2000), de Castro (I988, 2000), Fausto (2010).

${ }^{14}$ Hubo resistencia en muchos Estados en contra de la elección de interventores, muchos de los cuales eran foráneos. El caso más serio ocurrió en São Paulo, cuya sociedad se negó a aceptar al interventor señalado por el gobierno central. En I932, lideró un movimiento en favor de una mayor autonomía de los Estados y de un retorno del Estado de derecho: "El movimiento que ha comenzado [...] no tiene otra intención que reintegrar el orden legal del gobierno y dar a los brasileños la posibilidad de retomar sus derechos y franquicias que son el sello de nuestra civilización" (Carone I973: 53). El movimiento debió haber contado con la participación de Minas Gerais y Rio Grande do Sul, pero al último minuto estos dos Estados se mantuvieron leales al gobierno central y São Paulo debió enfrentar a las tropas federales con otros aliados. Aun cuando fue derrotado el movimiento sirvió como una alerta al gobierno federal, el cual ahora nombró como interventor a un representante de la burguesía de São Paulo y comenzó a responder con mayor atención las demandas del Estado. Después de la denominada Revolución Constitucionalista de I932, hubo un mayor apoyo federal para los productores de café. 
Constitución de 1934, Vargas fue elegido, a través de una elección indirecta, para un período que duraría hasta I938. En noviembre de I937, cuando la campaña electoral estaba en plena marcha con el mismo Vargas compitiendo como candidato presidencial, este decidió provocar un golpe de Estado forzando al Congreso a imponer una nueva Constitución y a abolir las elecciones. ${ }^{15}$ Hasta su caída en I945, Vargas gobernó mediante decreto y sin una legislatura nacional. Si en su período inicial el régimen de Vargas fue autoritario, con la creación del Estado Novo en 1937 se movió hacia un Estado más represivo. Durante esos años se suspendieron las libertades civiles, se llevaron a cabo encarcelamientos arbitrarios, se censuró totalmente a la prensa y se instauró una extensa máquina propagandística. ${ }^{\mathrm{I}}$

El ritmo estructural reformista no hizo más que aumentar con el Estado Novo. Debido a que el Congreso estaba clausurado y los enemigos amordazados, Vargas fue capaz de introducir cambios importantes sin mayor oposición. Estas reformas se consolidaron durante la década de I940, dando paso a nuevas instituciones estatales y a un nuevo cuadro de funcionarios civiles que, gracias a su habilidad, dieron más poder al Estado central (Sola I969: 269). El Departamento Administrativo do Serviço Público (DASP), creado en 1938, fue una institución clave en estas reformas. Gracias a éste, se reorganizó la estructura estatal y se formó una burocracia gubernamental técnica y profesional. ${ }^{17}$ Además, éste elaboraba y controlaba el presupuesto público y ejercía un papel relevante como consejero general del gobierno. El DASP tenía sedes en los distintos Estados y, junto con los Interventores que Vargas nombró para controlar a los gobiernos locales (reemplazando a los gobernadores

is "La Constitución de I937, [...] no dejó nada de la vieja constante del liberalismo. Se trataba de una dictadura política completa por parte del presidente de la república" (Bello 1976: 315-17). Véase también Loewenstein (1942: Cap. 2), Levine (1998).

${ }^{16} \mathrm{~A}$ pesar de que el régimen entonces establecido se asemejaba al fascismo, con muchos de sus miembros mostrando una gran simpatía por dicho tipo de gobierno, su representación política en Brasil -integralismo- fue también puesto fuera de la ley en 1938, después del asalto a la residencia del presidente cuyo objeto era derrocarlo. Los integralistas, quienes esperaban ser incorporados al gobierno fueron eliminados del proceso político del Estado Novo. Después de cerrar el Congreso, disolver los partidos políticos y suprimir a la izquierda, el gobierno eliminó a los integralistas fascistas, la última fuerza organizada de participación política (Diniz I98I; Sola I969: 257-84; Levine 1998).

${ }^{17}$ Además de crear el Servicio de Carrera Civil con reglas de reclutamiento, el DASP estableció estándares para coordinar el proceso administrativo. Muchos de los líderes de las iniciales caixas de pensión serían también motores principales de los diversos ministerios e Institutos creados por Vargas (Malloy I979). 
elegidos popularmente), era el responsable de la administración de los Estados. Con ello, contribuyó al proceso de centralización llevado adelante por el gobierno central (de Souza I983).

Al mismo tiempo, el régimen de Vargas creó numerosas organizaciones ejecutivas y de carácter consultivo para apoyar las acciones del gobierno federal. Además del Departamento Nacional del Café, muchos otros cultivos tenían Institutos formalmente establecidos. ${ }^{18}$ El gobierno se enfocó también en el desarrollo de programas, generando nuevos ministerios para fortalecer las áreas de educación y salud. Al estar el gobierno influenciado tanto por la ideología fascista como por una resurgida Iglesia Católica existía bastante preocupación frente al cambio de orientación de la educación privada y pública. Aun cuando durante la República no prosperó una religión estatal oficial, la Iglesia Católica encontró apoyo en el régimen de Vargas, quien, en I93I, decretó la introducción de la educación religiosa en los colegios públicos. Así, durante el mandato de uno de los individuos más pro-fascistas y pro-católicos del Estado Novo, el Ministro de Educación Gustavo Capanema, se dio una intensa discusión sobre la necesidad de contar con una moral y una cultura cívica específicas. También creció considerablemente la educación secundaria privada, aunque la primaria y la universitaria no aumentaron mayormente (Schwartzman et al. 1984).

A pesar de los debates ideológicos y las discusiones sobre la reorganización administrativa, los avances educacionales fueron menores. Para I932, sólo 2.3 millones de estudiantes asistían a los colegios del país, representando aproximadamente a un cuarto de la población menor o igual a veinte años. Aún más, muy pocos de los estudiantes que estaban matriculados se encontraban en colegios secundarios. Un $5 \%$ estaba inscrito en algún tipo de educación secundaria, y sólo un $2 \%$ en estudios superiores (que incluían colegios normalistas educando a profesores de colegios primarios y secundarios). En los siguientes 23 años se produjeron algunos cambios, pero a paso lento. La educación primaria creció un 2,I\% anualmente, un poco más bajo que el crecimiento nacional de la población. La terciaria, en tanto, creció a un $0,5 \%$ y la secundaria, finalmente, alcanzó un 5,3\% por año (IBGE I947).

I8 Estos eran llamados Instituto do Açúcar e do Álcool, Instituto do Mate, Instituto do Pinho, Instituto Nacional do Sal e Instituto do Cacau da Bahia. 
Incluso para 1940, el número de estudiantes matriculados por grupos de edad era extremadamente bajo. El censo de ese año registró que sólo un $26 \%$ de los niños entre 7 y I8 años estaba inscrito en un colegio y las niñas de esa edad llegaban al 25\%. Al desglosar esos porcentajes por edad y nivel de enseñanza, la educación primaria y pre-colegial (en total, ocho años de escolaridad) tenían más o menos la misma proporción de estudiantes que personas jóvenes del total de población. Sin embargo, la proporción de los niños que atendían los cuatro últimos años de los colegios secundarios alcanzaba un I0\% para los hombres y sólo un 8\% para las niñas de esa edad. Este bajo nivel de enseñanza significó que el nivel de analfabetismo se mantuviera particularmente alto. Si en el censo de I920 los alfabetizados alcanzaban un 34,8\% de la población adulta mayor o igual a ı8 años, en el censo de I940 dicha cifra había subido sólo al 43,6\% (IBGE I947).

Los diversos esfuerzos de Capanema para mejorar la educación terciaria fueron bloqueados por su temor a que la oposición liberal se afianzara en dichas instituciones. La primera universidad formal creada en Brasil se fundó en el Estado de São Paulo gracias a iniciativas privadas. Aunque desde el siglo XIX Brasil contaba con facultades de Medicina, Leyes e Ingeniería, no existía ninguna universidad propiamente establecida. No obstante, en I933 industrialistas y líderes políticos de São Paulo lograron organizar la Universidad de São Paulo luego de combinar varios Institutos con la nueva Facultad de Ciencias y Letras. Esta primera universidad brasileña fue liberal, laica, pública e inicialmente siguió la línea de una universidad francesa estándar. En efecto, Francia envió una misión de distinguidos académicos para colaborar en su conformación, entre los cuales se encontraban Claude Lévi-Strauss y Fernand Braudel. Así en el primer año de estudio la Facultad de Filosofía contaba sólo con académicos europeos entre sus filas, los cuales provenían de Francia, Italia y Alemania y enseñaban en todas las carreras científicas y científico-sociales. Esto revolucionó por completo la enseñanza superior brasileña, lo que explica por qué esta Facultad tomaría años en ser una parte central de la Universidad y por qué demoraría tanto en conseguir su independencia de Ingeniería, Minas, Leyes y Medicina. Con todo, la Facultad de Ciencias y Letras, junto al Instituto Osvaldo Cruz de Río de Janeiro, deben ser consideradas las verdaderas pioneras de la ciencia brasileña (Schwartzman ı991: Cap. 5). 
Ahora bien, en un área fundamental de la educación el régimen de Vargas sí realizó un desarrollo considerable, y éste, valga la paradoja, no provino del Ministerio de Educación sino del Ministerio del Trabajo; se trata del primer programa industrial serio de Brasil. En I939, al momento de decretar que las grandes compañías con 500 o más trabajadores tenían que proporcionar instalaciones de comisaría, el gobierno también ordenó que dichas empresas debían mantener 'cursos de desarrollo profesional' para sus empleados (Schwartzman et al. I984). Esta idea de una educación industrial financiada por privados fue, muy a pesar de los deseos del Ministerio de Educación, ${ }^{19}$ empujada tanto por el Ministerio del Trabajo como por la Federação das Indústrias do Estado de São Paulo (FIESP) liderada por Roberto Simonsen. Influenciados por las ideas alemanas del aprendizaje industrial moderno, los industrialistas empujaron para controlar un área completamente abandonada por el Estado hasta entonces. El resultado fue la creación en 1942 de lo que se transformaría en el sistema de educación industrial más grande del mundo: primero vendría el Serviço Nacional de Aprendizagem Industrial (SENAI) en nombre de la industria, y luego el Serviço Nacional de Aprendizagem Comercial (SENAC) por el del comercio. ${ }^{20}$ Los empresarios industrialistas convencieron al gobierno de crear un impuesto sobre los salarios con el fin de mejorar el sistema administrativo de las asociaciones privadas industriales en cada Estado. El SENAI rápidamente institucionalizó cursos de entrenamiento y, en los años siguientes, matricularía a miles de estudiantes en programas cortos y largos. Incluso educaría a un futuro presidente de la república. ${ }^{2 \mathrm{I}}$

El éxito del SENAI estuvo en muchos sentidos relacionado con uno de los cambios fundamentales ocurridos durante el gobierno de Vargas. En efecto, fue en el área de las relaciones laborales que el régimen de Vargas llevó a cabo los cambios más profundos en contraste con la ideología y actividades de los gobiernos de la Vieja República. Aun cuando compartió con los regímenes anteriores la forma violenta de suprimir a los movimientos de izquierda, Vargas también estableció una nueva política de cooptación de los trabajadores urbanos a través de una labor

19 Simonsen había sido una de los principales responsables, junto a Júlio de Mesquita Filho dueño de O Estado de São Paulo, y el líder político Armando de Sales Oliveira, del establecimiento de la Universidad de São Paulo (Schwartzman I99ı: Cap. 5).

${ }^{20}$ La FIESP, el SENAI y el SENAC fueron fundados en 1946.

${ }^{21}$ Sobre los orígenes del SENAI, véase Weinstein (I990: 379-404; 1996). 
legislativa moderna. Estas leyes incluían el derecho a organizarse en sindicatos, derechos laborales básicos para negociar y seguridad social. A pesar de que esta legislación provino de la iniciativa gubernamental y no de la presión ejercida por la clase trabajadora, reflejó la percepción del gobierno de que los trabajadores urbanos y sus organizaciones, especialmente en el sector industrial, se habían transformado en una parte importante de la escena nacional. Este fue un cambio fundamental en la Vieja República. ${ }^{22} \mathrm{Al}$ tiempo que esta cooptación disminuyó la autonomía de la organización laboral -llevando a que los sindicatos fueran controlados por el gobierno y a la cooptación de sus líderes- estas organizaciones pasaron a ser parte de la base política de Vargas. ${ }^{23}$ La figura carismática de Vargas, de hecho, derivó en gran medida de su control y manipulación del movimiento laboral aprovechado por el Estado.

La legislación laboral promulgada por Vargas era comprehensiva y fue un avance en el tratamiento de las relaciones laborales. Con la creación en I930 del Ministerio del Trabajo se desarrollaron una serie de normas legales que tuvieron por objeto ordenar las relaciones entre los sindicatos y el empresariado en cooperación con el gobierno. Es más, el gobierno adoptó la política denominada unicidade sindical, que institucionalizó un sólo sindicato por cada industria y/o municipalidad. ${ }^{24}$ Dicha legislación limitó el número de trabajadores extranjeros por empresa (la ley de tres tercios de trabajadores nacionales), regularizó el día laboral, garantizó el derecho a vacaciones y controló el trabajo de las mujeres y niños. También se crearon Convenções Coletivas de Trabalho $Y$ Juntas de Conciliação e Julgamento, las cuales estaban compuestas de re-

${ }^{22}$ Washington Luís afirmó que "la cuestión social es un caso para la policía". Aunque muchas veces citada, muchos autores han cuestionado la veracidad de esta frase. Véase French (2006: 379-416).

${ }_{23}$ "El Estado que emergió de la Revolución de I930 mantuvo la política fundamental de debilitar a las clases trabajadoras, reprimiendo duramente a sus vanguardias y a sus organizaciones partidarias; sin embargo, al mismo tiempo buscó establecer una nueva relación con dichas clases. La política, pura y simple, llevada a cabo por las antiguas clases gobernantes no tenía ya las condiciones para mantenerse por sí misma. En la plataforma de la Alianza Liberal ya había trazos de un interés mayor en el llamado problema social; el malestar de los trabajadores de los primeros años de la década de I930 llevó a 'sensibilizar' al gobierno en relación con esta cuestión” (Fausto I972: I07-8).

${ }^{25}$ En 1939, se originó la 'singularidad' o monopolio de la asociación laboral por unidad territorial, lo que llevó a la exclusión de más de un sindicato en las mismas áreas de trabajo. Esta regla, que en combinación con el impuesto sindical representa el aprovechamiento del poder de los sindicatos sobre el Estado, continúa hoy en día, aunque la Constitución establece la libertad de asociación de los trabajadores. Incluso el PT, que desde la oposición criticó la regla de la unidad sindical y el impuesto sindical, no se molestó en reformar la legislación cuando llegó al poder. 
presentantes de trabajadores y empresarios para hacer frente a contratos laborales y disputas. El Día del Trabajo se convirtió en un gran evento público y fue llamado el día del trabajador. Finalmente, en una gran ceremonia en el estadio Vasco de Gama de Río de Janeiro, Vargas firmó el primer decreto de salario mínimo en la historia de Brasil.

En I940, la creación del impuesto sindical -que proporcionaba ingresos a los sindicatos y eran recogidos y divididos por el Ministerio del Trabajo- representó un instrumento fundamental de cooptación entre el Estado y los sindicatos. ${ }^{25}$ Estas cuotas sindicales y el modelo de sindicato único por industria fueron utilizados para consolidar el apoyo laboral al gobierno. Estos gestos a favor de los sindicatos estuvieron, por supuesto, estrechamente controlados por el Estado corporativista diseñado por Vargas. El marco legal para ello fue la Consolidação das Leis do Trabatho (CLT), codificada durante el período del Estado Novo (I937-I945). De acuerdo con Skidmore, éste

[...] creó una estructura semi-corporativista en la cual los sindicatos estaban íntimamente atados al control federal. En primer lugar, todos los empleados cubiertos por la CLT estaban obligados a contribuir un monto (un jornal por año) deducible de su planilla salarial. El dinero iba directo al Ministerio del Trabajo y después era distribuido a los sindicatos, y los gastos eran supervisados por el Ministerio. En segundo lugar, todas las elecciones sindicales eran monitoreadas por el Ministerio, el cual debía validar los resultados. Podía incluso descalificar a los competidores. No sólo eso: todos los oficiales sindicales podían ser removidos por el Ministerio bajo reglas que eran abiertamente vagas. En tercer lugar, la ley convirtió a las huelgas virtualmente en ilegales, ya que casi todas las posibles disputas debían ser referidas al sistema de la Corte del Trabajo para tomar una decisión. En cuarto lugar, los sindicatos sólo podían ser formados para representar a una sola categoría dentro de un solo municipio [...]

También podía haber una federación (a nivel estatal) y una confederación (a nivel nacional) para dichos sindicatos. Pero negociar en cualquiera de ambos niveles iba más allá de lo legal. (Skidmore i988: 33-4)

${ }^{25}$ El impuesto sindical representaba una contribución en el monto de un día laboral de todos los trabajadores, sindicalizados o no. Los fondos conseguidos eran distribuidos entre los sindicatos que vivían gracias a esta contribución discrecional. Los sindicatos dependían, entonces, del Estado y no de las contribuciones de sus trabajadores sindicalizados. Este impuesto existe actualmente. 
Junto con apoyar y manejar a los sindicatos el gobierno de Vargas estableció nuevas instituciones nacionales de bienestar financiadas, controladas y patrocinadas por el Estado. Estas incluían no sólo la creación del Ministério do Trabalho Indústria e Comércio (que jugó un papel principal en la organización y control de los sindicatos e incluso patrocinó, como hemos visto, la educación industrial en una escala masiva), sino también la creación de un Ministério da Educação e Saúde independiente. Este cambio de la política social hacia las preocupaciones centrales del gobierno fue también acompañado de un discurso político e ideológico que justificaba el papel del Estado en la esfera social de la misma forma como había sido justificada su intervención en la economía. Era un programa que, para 1936, se había transformado, siguiendo a Skidmore, en un programa de "bienestar social nacionalista que era inequívocamente antidemocrático" (Skidmore 2007: 3I).

A pesar de que los primeros programas de pensiones comenzaron en la década de 1920 con la creación de los CAPs -los cuales tenían beneficios por pensiones, incapacidad, salud y muerte- dichos planes se extendieron a todo el servicio público sólo en I93I y a los mineros un año después. De a poco, cada sector económico recibió su propio CAP (Malloy I979: 40-50; Barroso I983: 39-44). Con el ánimo de estabilizar estas primeras Caixas, que a menudo no estaban basadas en principios actuariales y además solían tener problemas financieros, el gobierno de Vargas racionalizó el sistema a través de la integración de CAPs en Institutos más grandes (IAPs), reduciendo así su número pero asegurando pensiones para sectores enteros de la economía. Como muchos han señalado, el paso a las IAPs trajo un cambio significativo en el sistema de seguridad social desde una administración esencialmente privada a una principalmente pública y de compañías individuales a todo tipo de trabajadores (Cohn I98I: 8). La primera de estas IAPs fue creada en I933 para trabajadores del mar; en I934 vinieron los trabajadores comerciales y empleados bancarios; numerosos otros Institutos fueron organizados para otras industrias a lo largo de la década (Barreto et al. I997: 7). Además, en 1936 el gobierno se hizo cargo de los excedentes de los fondos recaudados por estas CAPs y los nuevos IAPs, invirtiéndolos en títulos de gobierno de todo tipo con el fin de crear un patrimonio de capital para los programas de pensiones (Andrade 2009: 7I-4). Gran parte de 
estos títulos estuvo involucrada en inversiones en industrias desarrolladas por el Estado y en la construcción de la nueva capital, Brasilia. En este sentido, Brasil actuaba como muchos otros Estados: aplicaba fondos excedentes a actividades industriales. ${ }^{26}$

En 1938 fue el turno de los transportistas y para I939 existían 98 CAPs y cinco Institutos que aseguraban a cerca de I.800.000 trabajadores, todos los cuales estaban bajo el control del Ministerio del Trabajo. Para I945, estos Institutos y Caixas fueron reducidos a sólo 35 para hacerlos más eficientes, y el número de afiliados alcanzó 2.800 .000 personas, con 235.000 beneficiarios. Esto significó un cambio sustancial en comparación con los 140.000 inscritos en planes de pensiones con anterioridad a la Revolución de I930 (Oliveira y Fleury i986: 342).

Como parte de este nuevo gasto social por parte del Estado, el gobierno también llevó a cabo iniciativas en políticas de salud, aunque en este caso se siguió un camino menos revolucionario, pues las administraciones imperiales y de la Vieja República habían apoyado constantemente iniciativas de este tipo. Desde los inicios, la salud pública fue una preocupación central del gobierno; primero en los puertos y la capital imperial, luego en los territorios y finalmente en los Estados y municipalidades. El hecho de que los primeros líderes del movimiento sanitario hayan sido importantes líderes científicos brasileños con conexiones profundas entre la élite política ayudó a empujar las cuestiones de salud a la vanguardia de las preocupaciones del gobierno federal. Brasil experimentó una ola de epidemias que se extendieron a lo largo del país durante todo el siglo XIX. Las epidemias de fiebre amarilla en I849 y de cólera en I855-I856 obligaron al gobierno imperial y republicano a enfrentar explícitamente los problemas acarreados por la salud y sanidad públicas.

En I851, el gobierno creó un Consejo Imperial de Higiene Pública y en 1886 se estableció una Inspectoría General de Higiene más poderosa, la cual tenía control sobre los inspectores en los puertos y elaboraba

${ }^{26}$ Como algunos investigadores han señalado, la seguridad social desde la década de I930 tuvo como componente esencial la captura de ahorros forzosos para ser utilizados en industrialización y otros proyectos estatales (como la construcción de Brasil, el financiamiento de la Companhia de Vale do Rio Doce y la Companhia Siderúrgica Nacional), como también para maximizar el apoyo político para los regímenes que estuvieran en el poder (Barrueto et al. I999). Que este no era un comportamiento atípico puede verse en la experiencia mexicana cuando en la década de I940 se estableció un Estado de Bienestar bajo el gobierno de Miguel Alemán. También puede compararse con el Estado fascista de Mussolini en los años I930. Véase Spalding (I980: 4I9-38) y Quine (2002: II5). 
estadísticas vitales estatales. Incluso durante la República, que devolvió muchas de las responsabilidades del gobierno central a los Estados, la administración federal reforzó a las instituciones nacionales de salud pública. En I902, Oswaldo Cruz, el científico más reputado de su época, organizó en el Estado de Río de Janeiro una campaña para enfrentar a la fiebre amarilla, y en I9O4 fue nombrado jefe de la Directoria Geral de Saúde Publica Nacional. Pronto le siguieron campañas nacionales contra esa y otras epidemias como la plaga bubónica y viruela, además de una ley que decretó la vacunación obligatoria de toda la población para hacer frente a esta última enfermedad. Luego, en las décadas de I9ıо y I920, el gobierno apoyó la creación de un registro nacional de enfermedades junto con una lista de medidas para mejorar la salud pública. En I923, otro científico importante, Carlos Chagas, ayudó a fundar un nuevo Departamento Nacional de Saúde Pública. Durante su dirección el gobierno nacional promovió la salud materna e infantil, comenzó a trabajar en accidentes industriales y en la salud rural, en registro de medicamentos y en una serie de otras actividades relacionadas con la salud pública. Finalmente, junto con la organización de los primeros grupos de pensiones y retiros en la década de I920 se desarrolló también un movimiento para crear clínicas locales que practicaran la medicina preventiva, las cuales estaban vinculadas a los nuevos IAPs y CAPs. Muchos de estos fondos de pensiones mantenían hospitales y clínicas ofreciendo generalmente mejores servicios médicos para sus miembros que aquellos prestados por las municipalidades y otras agencias gubernamentales.

El derrocamiento de la Vieja República por parte de Vargas fortaleció aún más a los grupos de Salud Pública pertenecientes al gobierno central. En I930, se organizó dentro del Ministério da Educação e Saúde una sección separada de salud que, cuatro años después, combinó la sección Salud con la Directoria Nacional de Saúde e Assistência Médico Social (DNSAMS). Bajo su tutela quedaron reunidos los diversos Directorios y Servicios que trabajaban con hospitales, el control sanitario de los puertos, el Distrito Federal y las numerosas campañas formales de inoculación en contra de enfermedades específicas en ciertas áreas. Estas campañas, que parecen haber estado inactivas en el período I930I934, tomaron un nuevo impulso en el período post I935, muchas veces con la ayuda de la Fundación Rockefeller. En 1937, la Subsecretaria de 
Salud Pública Federal, conocida como el Departamento Nacional de Saúde (DNS), asumió la coordinación de todos los departamentos de salud estatal, creándose además un fondo especial de salud pública en todas las municipalidades bajo dirección federal. Al mismo tiempo, comenzaron los primeros intentos serios por financiar e implementar clínicas rurales. ${ }^{27}$

Como muchos de los ideólogos del movimiento autoritario de modernización, Vargas se preocupó del mejoramiento de la población brasileña. Dicha ideología incluía el blanqueamiento de la población y una consecuente hostilidad racial contra negros y mulatos. Incluyó, asimismo, un impulso importante para enfrentar la salud de los niños, como parte esencial del intento por crear un 'nuevo hombre' en Brasil. En un mensaje navideño a la nación en I932, Vargas llamó a los interventores estatales que había designado de entre los gobernadores a preocuparse por la mortalidad infantil, los niños abandonados y la delincuencia juvenil. Ese año, el gobierno convocó una Conferência Nacional de Proteção à Infância, y en 1934 institucionalizó la Diretoria de Proteção à Maternidade e à Infância. La cuestión de protección y salud infantil-juvenil fue incluso mencionada en la Constitución Política del Estado Novo, que estableció el cuidado de los niños como responsabilidad del Estado (Oliveira I993: IOI-2).

Así, el gobierno federal mantuvo su posición dominante en la salud pública a lo largo de las décadas I930 y I940, y en I953 todos estos esfuerzos fueron finalmente coordinados en un Ministerio de Salud. El nuevo Ministerio asumió el control sobre todo tipo de actividades, desde la conformación de estadísticas hasta el entrenamiento educacional de los trabajadores de la salud; desde la creación de escuelas de enfermería y la financiación de institutos de investigación hasta la evaluación de la calidad de medicinas producidas en el país.

El gobierno de Vargas también desarrolló por primera vez en la historia de Brasil una política de viviendas públicas. Creó las llamadas carteiras prediais en los diversos Institutos y Caixas para dar créditos subsidiarios a los trabajadores por concepto de construcción de sus casas. Estas carteiras fueron con posterioridad fusionadas con la Fundação da

${ }^{27}$ Sobre las reformas de salud de este período, véase Oliveira (2007). Para las muy activas relaciones en salud llevadas a cabo por Vargas, véase Vieira de Campos (2006), Faria (2007). 
Casa Popular, una institución federal que permitió al Estado construir casas subsidiadas y facilitar el financiamiento de las viviendas. A pesar de que esta última institución no fue particularmente exitosa, para fines de los años I940 las IAPs, CAPs y la Fundação habían construido unas I40.000 habitaciones. Al mismo tiempo, el gobierno de Vargas intervino crucialmente en la otrora sacrosanta área de la propiedad privada. En I942, a través de un decreto, el gobierno congeló el alquiler de las residencias y reguló las relaciones entre propietarios e inquilinos, en beneficio de éstos. Debido a que en I920 cerca del 81\% de los edificios en la ciudad de São Paulo estaban habitados por arrendadores, este decreto significó un cambio vital en las actitudes libremercadistas de regímenes anteriores (Bonduki I994: 7II-32).

Estas iniciativas sociales y económicas del gobierno forjaron la base de un Estado de Bienestar moderno, aunque éste todavía cubría a una porción menor del sector urbano. Sin embargo, este fue un cambio sustancial en comparación con la ideología liberal. Las ideas e instituciones formadas por Vargas influenciarían profundamente el desarrollo del Estado de Bienestar brasileño con posterioridad a I950. No es sorprendente, pues, que todos los gobiernos que sucedieron a la era de Vargas, militares o democráticos, fueran influenciados por los cambios introducidos durante su mandato. Los gobiernos post 1950 no dudaron en intervenir en la economía y su compromiso con la industrialización creció aún más con el paso de los años. Tampoco disminuyó la preocupación por las cuestiones sociales, ya que todos los nuevos gobiernos tomaron en cuenta el creciente poder de las clases trabajadoras y la importancia de las clases medias urbanas para conseguir estabilidad y apoyo a cualquier régimen que buscara la eficiencia. En Brasil, el gobierno era visto ahora como el actor principal en la economía y la sociedad, y no cabe duda que los orígenes de dicho pensar se encuentran en las ideas y prácticas emergidas en las dos décadas del período de Vargas.

Los cuarenta años transcurridos desde el derrocamiento del Estado autoritario de Vargas hasta el retorno de la democracia estuvieron marcados por el hecho de que muchas de las cuestiones que llevaron a Vargas al poder continuaron siendo debatidas, discutidas y, a veces, completamente resueltas. Algunas de estas cuestiones decían relación con cómo industrializar una economía en desarrollo, cómo incorporar a la 
nueva fuerza laboral urbana y cómo resolver las extraordinarias desigualdades en la distribución del ingreso y la riqueza. Tanto los populistas demócratas post Vargas como los oficiales militares debieron enfrentar estos desafíos. Sus propuestas y soluciones diferirían. No obstante, sin importar si el sistema era represivo o democrático, todos los regímenes compartían características sorprendentemente similares en cuanto a cómo debía funcionar la economía y la sociedad luego de introducir sus soluciones. Ya se tratara de un intento vertical por parte de los militares de educar y modernizar a la sociedad a costa de los sueldos y derechos de los trabajadores o de un régimen democrático cuyo objetivo fuera constituir un Estado de Bienestar moderno mediante una mejor distribución del ingreso, todos debieron resolver las cuestiones relacionadas con la transformación de Brasil desde una sociedad altamente estratificada y predominantemente rural a una preferentemente urbana e industrializada. ${ }^{28}$

De acuerdo con el censo de I960, existían en Brasil Iıo.000 establecimientos industriales, empleando a r.800.000 trabajadores, de los cuales casi el $4 \mathrm{I} \%$ trabajaban en las áreas de textiles, vestimentas, comida y bebestibles. ${ }^{29}$ Este sector de industria liviana, que en 1949 representaba la mitad del valor de la producción industrial, ahora alcanzaba sólo un tercio de dicho valor. En el mismo período, la metalurgia, los equipos manufactureros, el transporte de material industrial y la industria química aumentaron su participación relativa, alcanzando cerca de un tercio del valor de la producción industrial. Si se cuantifica a través del número promedio de trabajadores empleados (que era de i 6 trabajadores por fábrica), algunos sectores como el textil, el caucho, la electricidad y equipamiento de comunicaciones, el farmacéutico, papel y cartón, empleaban en promedio a más de cincuenta personas. Las transformaciones económicas experimentadas entre 1930 y I960 tuvieron un impacto en la población económicamente activa, como también lo tuvieron los cambios en las asignaciones productivas. El empleo en el sector agrícola creció menos que el de la industria y servicios, el cual en ig6o empleaba a un tercio de la población económicamente activa en comparación con un I3\% en la industria y un 54\% en la agricultura (Merrick y Graham i979: 64-5).

${ }^{28}$ Para una reseña general sobre este período, véase los dos tomos de Vidal Luna y Klein (2006 у 2013).

${ }^{29}$ En I939 y I949 los mismos sectores empleaban un 55\% y un 51\% respectivamente. 
En abril de 1964, después de un período de turbulencia política, el ejército dio un golpe de Estado y estableció una dictadura que duraría veintiún años. El 9 de abril, el régimen militar recientemente instalado promulgó el primero de una larga lista de 'actos' que transformaron al Estado democrático en uno autoritario. El llamado decreto AI-I dio al Congreso el poder de elegir al nuevo presidente y nombró a Marshal Castelo Branco para el puesto, uno de los principales líderes del golpe. En vez de recurrir a sus aliados civiles, los militares, por primera vez, decidieron desarrollar su propio proyecto político bajo un control total por parte del ejército. La represión política comenzó a ser la norma: los militares arrestarían a miles de personas, incluyendo a oficiales disidentes. El gobierno fue especialmente duro con los líderes de los movimientos de los trabajadores y rurales. Durante el régimen militar, se generalizaron la censura, la represión, el encarcelamiento y la tortura. ${ }^{30}$

Los regímenes militares que controlaron el país en este período autoritario exhibieron características únicas. Por una parte, eran represivos, abiertamente anticomunistas y aliados incondicionales de Estados Unidos en la Guerra Fría. Por otra, estaban determinados a organizar un Estado centralizado, dominado por el Ejecutivo, limitando los otros poderes federales como también el campo de acción de los Estados y municipalidades. Los militares mantuvieron las elecciones y el Congreso continuó en operación. Sin embargo, los poderes de la legislatura fueron reducidos y sus miembros fueron controlados a través de la purga de legisladores de izquierda y de centro que se oponían a las directrices emitidas por el Ejecutivo o eran críticos del régimen. Los derechos de estos políticos fueron anulados (cassados).

Los militares no constituían un grupo homogéneo. Existían divisiones internas y diferentes puntos de vista sobre el nivel de centralización del sistema, la duración de la intervención militar y los fines utilizados para llevar a cabo su programa. Para algunos, la represión, la censura y la tortura eran acciones extremas que debían usarse sólo en última instancia; para otros, eran herramientas fundamentales para destruir a la izquierda. Ahora bien, a pesar de estas posiciones conflictivas, la represión y la tortura se convirtieron en parte fundamental del régimen. La disputa

$3^{\circ}$ Existe una extensa bibliografía sobre el periodo militar. Se pueden obtener visiones generales de los siguientes trabajos: Skidmore (I976, I988), Schmitter (I976), Linz (I976), Lamounier (I985), Stepan (I985), Morreira (I984). 
entre los grupos militares parece haber sido más intensa en períodos de elecciones presidenciales (otra particularidad de la dictadura brasileña). Temiendo la aparición de un régimen personalista bajo el dominio de algún jefe que pudiera mantenerse en el poder, los militares se comprometieron a adoptar períodos presidenciales fijos y 'elecciones' formales aunque no democráticas. A lo largo del período militar, el Congreso organizó un tipo de elección presidencial que esencialmente confirmaba la selección realizada previamente por los militares. Los conflictos internos en la elección de nuevos presidentes eran controlados por el ejército. Esto llevó a que diferentes grupos de militares se alternaran el poder y que, a pesar de dichos conflictos, el ejército fuera capaz de alcanzar el consenso que les permitió mantenerse en el gobierno.

En términos laborales y económicos, el nuevo régimen militar provocó cambios fundamentales. Uno de los más importantes de estos cambios fue la promulgación de una nueva ley salarial debido principalmente a su impacto inmediato en el crecimiento de los sueldos y en la distribución del ingreso. Antes de que esta legislación fuera aprobada, los salarios habían sido ajustados anualmente considerando la inflación real del período. La nueva legislación corregiría estos sueldos de acuerdo con una fórmula que consideraba tanto la inflación pasada, como también la estimada para los próximos doce meses (Simonsen 1970: 26-7). Debido a que la inflación futura era tradicionalmente infravalorada, esta legislación causó una baja sistemática en los sueldos, con sus consecuentes efectos negativos. Esta reducción deliberada en los sueldos reales, los denominados 'sueldos exprimidos', restringió la demanda agregada y el costo de mano de obra en el sector privado. La legislación introducida en un régimen altamente represivo (que incluía el control de las actividades sindicales) causó una reducción significativa en los sueldos reales. Así, por ejemplo, el promedio del sueldo mínimo real anual indexado a roo en 1964, cayó a 82 en I977, a pesar del rápido crecimiento que debió haber ocurrido en el período considerando que el PIB creció ¡i $90 \%$ entre I964 y I977! (véase el Gráfico I). Esta baja salarial habría sido imposible de implementar en un régimen democrático con sindicatos libres. Parece claro que el descenso de los salarios fue más abrupto en el primer período y que en el último gobierno militar se intentó compensar a los trabajadores de salarios más bajos otorgándoles sueldos por encima de 
la indexación de la inflación. ${ }^{3 \mathrm{I}}$ Aun cuando la tasa fue afectada por la inflación y las condiciones económicas, al parecer esta política salarial influyó también el aumento constante de las tasas de pobreza, las que en I983 alcanzaron un 49\% (véase el Gráfico 2).32

\section{- GRÁFICO 1, ÍNDICE DE SALARIO MÍNIMO REAL, 1960-1977}

(1964=100)

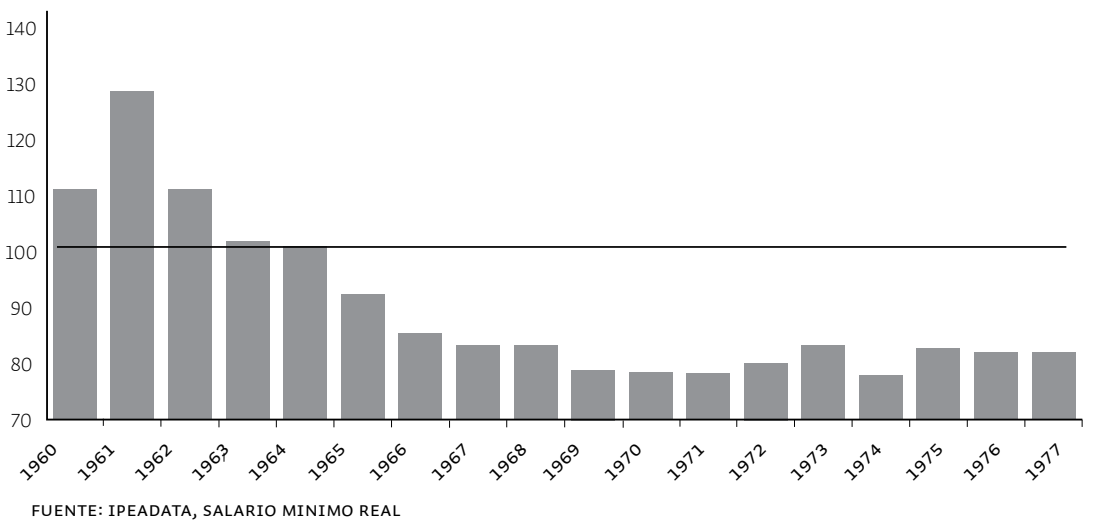

- GRÁFICO 2, PORCENTAJE DE POBREZA Y EXTREMA POBREZA EN BRASIL, AÑos SELECCIONADOS $1976 / 2009$

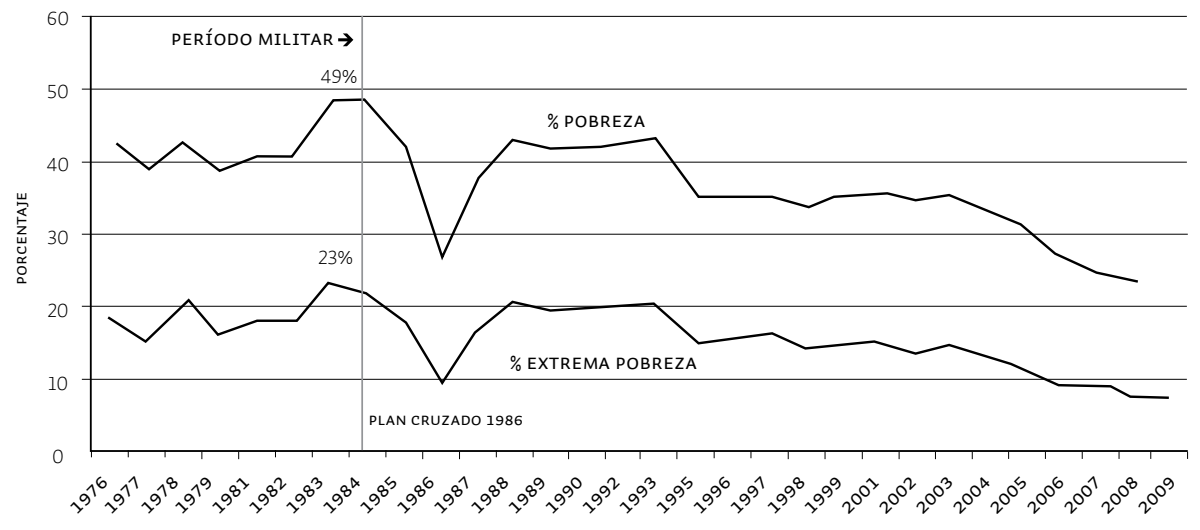

FUENTE: IPEADATA

${ }^{31}$ Desafortunadamente no existe información detallada de promedios salariales para este período. Para este tema véase Saboia (I990: 58I-600; 2000), da Jornada (I989: 65- 78).

${ }^{32}$ En este período ocurrió un extenso debate sobre la cuestión de la concentración del ingreso. El gobierno afirmó que los altos niveles de desigualdad de la distribución del ingreso eran un fenómeno transitorio causado por el proceso de crecimiento, mientras que otros economistas sostuvieron opiniones diferentes. Algunos argumentaron que existían razones estructurales para esta distorsionada distribución y que no sería eliminada con mayor crecimiento; otros culparon a la represiva política salarial del gobierno como la causa de esta concentración. Sobre este tema véase Langoni (I973), Fishlow (I972), Bacha y Taylor (I980), Ramos y Almeida (2000: 2I-45). 
Los regímenes que siguieron al período de Vargas no sólo extendieron sus políticas sino que también debieron lidiar con las relaciones que su gobierno había concretado con las nuevas clases populares urbanas. Claramente, el auge de un movimiento laboral radicalizado fue uno de los factores principales que explican la llegada en ig64 de los militares al gobierno. Asimismo, los militares fueron desafiados por diversos líderes civiles populistas que deseaban emular a Vargas y su habilidad para generar apoyo popular en el período I954-I964. Sin embargo, por muy temerosos que fueran los militares de las instituciones políticas desarrolladas por Vargas, estaban comprometidos con su visión de un Estado industrial moderno. En consecuencia, debieron resolver una serie de cuestiones sociales durante los años de baja en los sueldos, a la vez que necesitaron obtener el apoyo de las cada vez más poderosas clases medias urbanas.

El período del gobierno militar fue, así, una era de profundos e inusuales cambios sociales. Muchos de estos fueron inducidos por la industrialización y el aparejado crecimiento de una sociedad urbana; procesos que precedieron al gobierno militar que se intensificaron durante este período. Otros cambios fueron provocados por políticas llevadas a cabo por los militares, y otros fueron exógenos al cambio del régimen. Entre las transformaciones más importantes se contaban aquellas relacionadas con las políticas gubernamentales diseñadas para hacer frente a las consecuencias sociales de la industrialización y la rápida urbanización. Dicha industrialización tuvo efectos positivos y negativos. Generó una veloz movilidad social, quizás la más rápida y abierta en la historia de la nación, ya que emergió una élite industrial y administrativa entre la población educada del campo y en los sectores más marginales. No obstante, también produjo una migración interna masiva desde las zonas pobres a las más ricas del país, con el consecuente crecimiento de las áreas metropolitanas. La carencia de viviendas en los crecientes centros urbanos llevaría al nacimiento de las favelas, o asentamientos precarios, en las principales ciudades del país. Todo esto exigió una respuesta del gobierno, el cual, a través del Banco Nacional da Habitação (BNH), llevó a cabo un gran programa de vivienda e higiene. Al mismo tiempo, hubo un aumento importante del ritmo expansivo de la educación primaria y secundaria, cuestión que se explica en parte por los deseos de 
los militares de ganar el apoyo de la emergente clase media. Los militares promovieron también el acceso a la universidad y a la educación técnica. Finalmente, el gobierno compensó a los afectados por la baja en los salarios mediante la extensión del sistema de seguridad social, que incluyó avances significativos en la prestación de salud y pensiones. En efecto, los años del gobierno militar han sido definidos como el período en que Brasil logró establecer los fundamentos de un Estado de Bienestar moderno a través de la universalización de los servicios sociales y de la creación de instituciones federales poderosas. Con todo, este sistema estaba basado en modelos autoritarios y tecnocráticos, que serían transformados en la era post-militar. ${ }^{33}$

Dos de las áreas fundamentales de la acción del gobierno eran la educación y la investigación científica. A pesar de que con anterioridad a I964 la educación primaria y secundaria había experimentado un lento pero seguro avance bajo el régimen militar que impulsó estos dos sectores en I960, sólo un 73\% de los niños entre 5 y 9 años asistían a colegios primarios. Para i968, dicho porcentaje había aumentado a $89 \%$. Aunque no es posible contar con datos comparables para los años posteriores, en I985 el 79\% de los niños entre 5 y I4 años acudían a colegios primarios (Ribeiro 2008: 309). Inclusive, tanto la educación secundaria como la universitaria crecían de forma más rápida que en el período entre i960 y i980 (Schwartzman I99I).

Los cambios más dramáticos ocurrieron en el sistema educacional secundario. Mientras la educación primaria había crecido sostenidamente (siendo estimulada por una inversión constante), hubo una expansión y un cambio sustancial en la educación secundaria. Entre i963 y I984 se dobló el número de profesores secundarios, desde aproximadamente I20.000 a 2I5.000, mientras que los estudiantes aumentaron desde I.7 a 3 millones. El cambio más significativo se dio en el papel que empezó a jugar entonces el gobierno en el mercado secundario. En ig63, cerca del $60 \%$ de los estudiantes secundarios estaban matriculados en colegios privados; sin embargo, para i984 esta tendencia ya había sido revertida y un $65 \%$ de los estudiantes acudían a colegios públicos

33 Según Sonia Draibe (I993), este período marcó el establecimiento de un Estado de Bienestar en Brasil debido tanto a la universalización de los servicios, como a la creación de instituciones gubernamentales activas en todas las áreas definidas por el Estado de Bienestar moderno. A pesar de que este modelo sería profundamente reformado en el período post-militares, la estructura básica fue elaborada en las décadas de I960 y I970 (Draibe I993: I9-2I). 
(IBGE aeb_I964: 34I-2; aeb_I986: I74-5). Estos cerca de 3 millones de estudiantes secundarios representaban a un $22 \%$ de los jóvenes entre I5 y ig años, siendo que sólo un I2\% había estado registrado en 1972 (Ribeiro 2008: 309).

La expansión de los colegios secundarios, a su vez, llevó a una lenta expansión de los estudiantes universitarios. Para I984, existían 68 universidades en Brasil, 35 de las cuales eran federales, , o estatales, 2 municipales y 20 privadas; gracias a esto, la población universitaria creció de I42 mil alumnos en I964 a I.3 millones en I984, superando ligeramente el número de mujeres al de hombres (Martins 2000: 42-8).34 Dentro de este grupo, los programas de graduados habían doblado sus registros a 40 mil estudiantes para mediados de los años ochenta (Schwartzman I991: Tabla Io). El porcentaje de jóvenes entre 20 y 24 años que asistían a instituciones terciarias de educación -universidades y colegios técnicos- creció del $2 \%$ del total de jóvenes al I2\% entre I965 y I985 (Ribeiro 2008: 309). Este fue también un período en el que, por primera vez en su historia, el gobierno invirtió fuertemente en ciencia y tecnología. ${ }^{35}$

34 Para el desglose por sexo véase (IBGE aeb_I984: 25I, Tabla 2.6).

35 En I964, el Banco Nacional de Desenvolvimento (BNDES) estableció un fondo de io años para Tecnología con una inversión inicial de roo millones de dólares. Luego, en I974, el pequeño consejo de investigación nacional fue expandido y financiado de mejor forma, transformándose en el Conselho Nacional de Desenvolvimento Científico e Tecnológico (CNPq). Más temprano que tarde el gobierno militar estaba invirtiendo fuertemente en investigación de primer nivel, como también en infraestructura básica y desarrollo industrial (todo ello en nombre de un programa nacionalista). Comenzando en una fecha tan temprana como I953, el gobierno había creado un fondo de becas para estudiantes ligados en su mayoría a la ciencia. Este programa estaba dirigido por Coordenação de Aperfeiçoamento de Pessoal de Nível Superior (CAPES), el cual había sido fundado en I95I. Para la década de I960 varios cientos de científicos brasileños habían sido entrenados en universidades internacionales, especialmente en Estados Unidos e Inglaterra; a su retorno formaron un poderoso grupo de interés que presionó por la creación de laboratorios modernos y otras herramientas cruciales para lograr que Brasil compitiera en el nuevo escenario post Segunda Guerra Mundial. En I968, se implementó una nueva Ley de Reforma Universitaria, que estableció el sistema norteamericano de departamento y tres niveles de grados académicos, desde pregrados a magísteres y doctorados. Las universidades federales recientemente creadas en Minas Gerais y Brasilia fueron desarrolladas siguiendo este modelo; prontamente, se crearían este tipo de universidades en todos los Estados. Incluso el Estado de São Paulo había fundado dos años antes una nueva universidad en la ciudad de Campinas, con una importante participación de académicos extranjeros, la cual fue conocida como UNICAMP y rápidamente comenzó a competir con la Universidad de São Paulo como la universidad más relevante de la nación. UNICAMP fue diseñada desde el principio para ser un centro de investigación avanzada, sobre todo en física. Gracias a esto, muchos científicos brasileños trabajando en Bell Labs y universidades estadounidenses regresaron a trabajar en la nueva universidad. Por otro lado, el gobierno también creó una industria aérea y computacional, además de un programa de investigación nuclear tanto adentro como afuera de la universidad. Todo este esfuerzo llevó a Brasil a ser un jugador significativo en el mundo de las ciencias y, junto con India, fue uno de los pocos países del mundo menos desarrollado que pudo competir en ciencia moderna (Schwartzman I99I: Cap. 9). Sin embargo, la relación entre la comunidad científica no siempre fue pacífica durante el período militar. Muchos científicos fueron perseguidos, forzados a retirarse 
Todos estos incrementos en la enseñanza tuvieron un gran impacto en el alfabetismo. Para I940, sólo un 38,4\% de la población era alfabetizada, un número que para I950 había aumentado únicamente a 42,7\%. Sin embargo, en I970 los alfabetizados alcanzaban los dos tercios de la población y para I980 representaban al 74\% de los brasileños. Fue sólo en el censo de ig60 que los hombres y mujeres que sabían leer y escribir alcanzaron a la mayoría de la población (IBGE, Estatísticas do Século XX I98I). Una década antes, los alfabetizados de io o más años ya habían sido mayoría, pero solo los hombres y las mujeres alfabetizados no superaban el 44\%. Esos diez años fueron claves, porque en ig60 las mujeres alfabetas alcanzaron el $57 \%$ de la población femenina de ıo o más años, mientras que los hombres representaron el $64 \%$ de ese mismo grupo de edad (IBGE estatísticas do Século XX I965). Con todo, no sería sino hasta las década de iو80 que las mujeres alcanzarían los mismo niveles de alfabetización que los hombres, lo que se debió sobre todo a un aumento significativo de la asistencia femenina a colegios primarios y secundarios.

En las áreas tradicionales de la seguridad social el gobierno comenzó también un importante esfuerzo por modernizar y estabilizar fiscalmente el sistema de pensiones creado durante el régimen de Vargas. Al tiempo que el sistema era económicamente viable y obtenía mayores ingresos que gastos, para los años sesenta los costos estuvieron bajo el nivel de los gastos; empero, con el aumento de los trabajadores retirados, aquéllos excedieron pronto a los ingresos (véase Gráfico 3). El resultado pareció o mostró ser una potencial crisis fiscal que obligaría al gobierno a intervenir, en especial dado su control de las reservas financieras de estos Institutos. Aunque el sistema de seguridad social fue inicialmente financiado por trabajadores y empleadores, pronto incluyó la participación gubernamental. Sin embargo, tanto el fracaso del gobierno de cubrir completamente el sistema como el uso de fondos de reservas de pensiones por parte de los regímenes democráticos y militares para pagar los proyectos estatales y los programas del gobierno (vivienda, capita-

o expulsados. Aunque hubo mayor represión en las humanidades y en las ciencias sociales, los centros de investigación científica más importantes también fueron afectados; el Departamento de Física de Brasilia, por ejemplo, fue desmantelado luego de una invasión del campus universitario. La Sociedade Brasileira para o Progresso da Ciência (SBPC), el órgano principal de la comunidad científica de Brasil, llevó a cabo una oposición sistemática al gobierno militar, convirtiéndose en un importante grupo en el proceso de redemocratización del país. 
lización de las compañías públicas como la Compañía Nacional de Acero e incluso la construcción de Brasilia) generaron déficits, más aún cuando los beneficios fueron extendidos y el retiro en masa de los primeros beneficiarios tuvieron un impacto significativo en el flujo de ingresos. Ante la ausencia de suficientes reservas, el sistema se convirtió en uno de reparto en el que los contribuyentes de esos años pagaban por aquellos que se retiraban. Los desequilibrios de financiamiento fueron, así, producidos por fondos fiscales ordinarios que no identificaban la fuente.

- GRÁFICO 3: GASTOS COMO PORCENTAJE DEL INGRESO DE TODAS LAS CAJAS, INSTITUTOS E INPS, 1923-1969



Aun cuando existían varias formas de planes de retiro suplementario (aunque con numerosos problemas), en 1977 el gobierno decidió establecer regulaciones básicas para aquellos fondos de pensiones suplementarios que, a pesar de los muchos cambios ocurridos posteriormente, representaban todavía la base de la estructura existente. La Ley 6435/77 clasificó estos planes suplementarios en dos grupos: las Entidades Abertas de Previdência Privada (EFPPs) y las Entidades Fechadas de Previdência Privada (EAPPs). Los 'abiertos' fueron generados para todo individuo que quisiera unirse y pagar contribución. Los 'cerrados' estaban organizados por empresas en las que tanto los empleadores como los empleados contribuían y los cuales eran administrados por las compañías con una participación modesta de los empleados. En los primeros años los planes suplementarios tuvieron una actividad relativamente pequeña, especialmente los del tipo abierto. Pero en el caso de los planes 
cerrados (EFPPs) éstos entraron en vigencia incluso antes de la ley, y estaban concentrados en las grandes empresas estatales. Inicialmente, hubo un número reducido de dichos planes en el sector privado. Fue la mayor estabilidad económica la que permitió que ambos fondos se expandieran, atrayendo inversionistas individuales para los planes abiertos y estimulando a las grandes empresas privadas a crear sus propios planes cerrados. Aunque todo aquel que tuviera un registro na carteira (o estaba formalmente registrado como empleado en una empresa con un documento que indicara que ésta pagaba tanto la cuotas de las contribuciones de pensiones del empleado como las de la compañía) era parte también del sistema nacional de seguridad social, la ley de 1977 ofreció finalmente la posibilidad a individuos y compañías de dar planes suplementarios sobre una base sistemática y segura. Las compañías estatales y sus fondos de pensiones de empleados (EFPPs) acumularon activos significativos y pasaron a ser un actor importante del mercado de capitales nacionales (ABRAPP, ICSS, SINDAPP s/f). Para I985, el patrimonio de estos EFPPs era de 8.6 millones de dólares, el cual representaba el 2,6\% del PIB (Barreto de Oliveira y Ferreira 1997: 45). Fue sólo en I990 que la ganancia privada de los fondos abiertos comenzó a crecer, y fue sólo en i995 que las compañías de seguros extranjeras y privadas comenzaron a tener activos y contribuyentes significativos (Barreto de Oliveira et al. 2000: II). Mientras estos fondos abiertos crecieron rápidamente y alcanzaron activos equivalentes al 4,7\% del PIB en 2002, el patrimonio de las compañías sin fines de lucro del EFPPs aumentó a un I4,7\% del PIB (Beltrão et al. 2004: I9). Fueron, de hecho, los fondos del EFPPs los que se convirtieron en una parte importante del capital utilizado para privatizar al sector industrial en el período post-militar. Entre I994 y 2002 estos fondos aportaron un 7\% de los 87 billones de dólares usados para comprar estas compañías estatales. Es interesante observar que el gobierno, que en apariencia vendió sus acciones de dichas compañías estatales al sector privado, mantuvo una gran influencia en muchas de las empresas privatizadas gracias a la compra de numerosas acciones a través de los fondos de pensiones de las compañías estatales que se mantuvieron bajo el control del Estado. Aun cuando el monto invertido en fondos de pensiones no era una propiedad pública, sino que pertenecía a los trabajadores de una firma en particular, el gobierno 
mantuvo su influencia en las decisiones de gestión y en la inversión de los fondos controlados por los empleados públicos de estas empresas (BNDES 2002).

El programa público de pensiones, por otro lado, entró en crisis con el regreso del gobierno democrático. La Constitución de i988 creó el Régimen Jurídico Único para la administración pública. ${ }^{36}$ Hasta entonces, las cuentas de ingreso y de gastos de los funcionarios civiles no estaban incluidas en las cuentas públicas de pensiones. En la nueva Constitución todas las cuentas de pensiones públicas y privadas pasaron a formar parte del presupuesto del Instituto de Asistencia Social. Debido a que tanto los empleados civiles no pagaban por sus pensiones como a que cuando se retiraban recibían el Io०\% de sus salarios además de cualquier aumento que recibieran los empleados gubernamentales, ${ }^{37}$ no es sorprendente que el sistema de pensiones civiles estuviera permanentemente en déficit. La combinación de su esquema de pensiones con el sistema general de pensiones empeoró el financiamiento del sistema de seguridad social. Sin embargo, todos los gobiernos desde Vargas hasta la década de 1990 se endeudaron considerablemente con el sistema, el cual muy pronto entraría en nuevas crisis, especialmente después de la incorporación en I988 de empleados públicos que no cotizaban (Barreto de Oliveira et al. ı999: 8). Así, la necesidad de recuperación financiera del sistema de seguridad social era un proceso continuo, más aún cuando se expandía hacia nuevas áreas y absorbía una población más grande de contribuyentes y beneficiarios.

Al mismo tiempo, el gobierno militar claramente deseaba utilizar el sistema de seguridad social para aliviar la crisis causada por la rápida

${ }^{36}$ La implementación del Regime Jurídico Único (RJU) trajo mayores desequilibrios al sistema de pensiones, porque hasta entonces un largo número de empleados públicos era 'celetistas', es decir, estaban gobernados por las reglas de pensiones ordinarias de los trabajadores con pensiones privadas. Pagaban y retiraban sus contribuciones, utilizando reglas normales de pensiones, las cuales eran bastante menos favorables que el bienestar de los empleados civiles regulares. Pero cuando estos empleados gubernamentales 'celetistas' se unieron al RJU comenzaron a tener las mismas pensiones y beneficios completos que el resto de los empleados públicos. Esto, por supuesto, aumentó el déficit del sistema público que ahora formaba parte de la cuenta de pensiones ordinaria.

37 Aun cuando habían algunas contribuciones gubernamentales que normalmente financiaban las pensiones de los trabajadores estatales, la contribución general específicamente enmarcada para los empleados públicos fue establecida sólo en I998 a través de la Reforma Constitucional 20/98. Sin embargo, incluso con esta contribución específica, debido a las demasiado generosas reglas de retiro (las cuales igualaban a los empleados gubernamentales retirados y activos en términos de sus sueldos y beneficios), el segmento de las cuentas de pensión consagrado a los trabajadores fiscales continuó en déficit. 
industrialización y sus políticas de baja en los salarios, como también para conseguir el apoyo de la clase media al gobierno, que sería el primer grupo en beneficiarse masivamente de estos cambios en el sistema de seguridad social. Con este fin, el gobierno militar buscó consolidar la dispersión de las instituciones y agencias y expandir la cubertura de la población en riesgo bastante más allá de las industrias que habían sido cubiertas con anterioridad. La resultante reforma básica del sistema de pensiones llevaría a una expansión y a una centralización de las pensiones bajo el control gubernamental. Considerando que los militares centralizaban el proceso de decisión, dejando poca autonomía a las administraciones locales y estatales, no es de extrañar que una de sus principales reformas fuera la consolidación del hasta entonces fragmentado, limitado, disperso y pobremente financiado sistema de seguridad social. De acuerdo con un académico, esta reforma representó una de las características que definieron a los regímenes militares, en particular su centralización financiera y administrativa (Arretche I999) $3^{8}$ Con todo, también crearía un sistema fiscal mucho más seguro, permitiendo al gobierno expandir masivamente el Estado de Bienestar. Lo que los militares no hicieron, como muchos estudiosos han notado, fue usar el programa de bienestar social para resolver cuestiones relacionadas con la distribución del ingreso. En efecto, a pesar de la movilización social lograda en el período del 'milagro' brasileño, el país continuó siendo uno de los más desiguales del mundo en términos de distribución del ingreso.

Justo antes del comienzo del gobierno militar, en I960, la presidencia de Goulart había organizado el primer plan nacional de seguridad social (Ley 3807 de I960) llamado la Lei Orgânica da Previdência Social.39 Tres años después, hizo el primer gesto serio para asegurar a los trabajadores rurales a través del Fundo de Assistência ao Trabalhador Rural (FUNRURAL: Ley 42I4). Inicialmente, sin embargo, no se avanzó mayormente en esta área, cuestión que cambiaría únicamente con la

${ }^{8}$ Un académico del sistema de seguro social fue tan lejos como para argumentar que el nuevo formato era un modo de organización y de toma de decisiones hipercentralizado. En el período post-militar uno de los mayores temas sería la necesidad de descentralizar el sistema en su totalidad, sobre todo lo relacionado con los servicios médicos (Draibe 2002).

${ }^{39}$ En I974, todas las personas sobre 70 años recibían el 60\% de un salario mínimo, pero debían probar que habían contribuido al plan nacional de pensiones por al menos doce meses. En la Constitución democrática de I988 este derecho de pensión se transformó en universal sin importar si el beneficiado había cotizado en el sistema de seguridad social o no. 
llegada al poder de los militares en abril de I964. De hecho, el primer Ministro del Trabajo conservador y su jefe de gabinete bajo el nuevo régimen militar eran conocidos expertos en seguridad social (Malloy I979: I24-5).

En 1966, el gobierno revisó la integridad del sistema y todas las IAPs individuales y CAPs fueron reemplazadas por el Instituto Nacional de Previdência Social (INPS). El resultado fue que los diferentes programas de pensiones fueron ahora unificados y el sistema en su totalidad logró una buena base de financiamiento. Además, el gobierno logró expandir de forma sistemática y efectiva su cobertura a una proporción incluso mayor de la población nacional. Para I968, dos años después de su fundación, el INPS, que cubría tanto a empleados y a trabajadores por cuenta propia, aseguraba a 7.8 millones de personas (IBGE, Estatísticas do Século XX 2003). En los años setenta, el INPS expandió sistemáticamente su cobertura sobre la fuerza laboral. En I97I, la cobertura se extendió a los trabajadores rurales, haciendo por primera vez al FUNRURAL una institución efectiva a través de lo que se llamó el PRORURAL, que comenzó a formar parte del primero. Este fue un cambio profundo y original en la historia del bienestar social brasileño. Por primera vez, el gobierno proveyó servicios y pensiones a personas que no contribuían al sistema de seguridad social. Se gravó la venta de productos agrícolas en áreas urbanas, al tiempo que se introdujeron impuestos a las compañías. En breve, los trabajadores urbanos fueron gravados con el fin de pagar a los trabajadores rurales no contribuyentes. Así, este cambio fue francamente distributivo. En segundo lugar, fue diseñado desde un comienzo para ser un programa universal que afectaba a todos los trabajadores rurales, sin importar su rango ni condición (aunque las mujeres fueron incluidas sólo en i988). Por qué el más represivo de los regímenes militares habría optado por un sistema redistributivo y universal es una pregunta difícil de responder. Proponemos que con la represión total de las ligas campesinas premilitares y el apoyo continuo de la concentración de la tierra había potencial para que se generara una violencia rural seria y que, por lo tanto, el gobierno se vio en la necesidad de ofrecer algún sustento a los trabajadores rurales y así conseguir seguridad en el campo. ${ }^{40}$

$4^{\circ} \mathrm{Un}$ buen estudio de todos estos debates y cuestiones relacionadas con este acto inusual puede consultarse en Garcia (20I0). Originalmente, el FUNRURAL pagaba una pensión que alca- 
Del mismo modo, el gobierno fomentó también la participación de nuevos grupos de trabajadores con el fin de que ingresaran al sistema de seguridad social. En I972, incorporó a los trabajadores domésticos, y en I973 obligó a los trabajadores por cuenta propia a ingresar en el sistema. Luego, en I977, el INPS pensado para trabajadores urbanos y para el mundo rural fue finalmente integrado al Sistema Nacional de Previdência e Assistência Social (SINPAS). La sección médica fue trasladada al Instituto Nacional de Assistência Médica da Previdência Social (INAMPS), mientras que otra organización fue creada para manejar las finanzas: el Instituto de Administração Financeira da Previdência e Assistência Social (IAPAS). ${ }^{4 \mathrm{I}}$ La inscripción de los trabajadores asegurados creció rápidamente bajo el nuevo INPS, y para I980 el sistema de seguridad social había triplicado el número de participantes asegurados a casi 26 millones de brasileños, tres veces el número de asegurados en el primer año de operación (IBGE, Estatísticas do Século XX 2003). De acuerdo con algunos académicos, "incluso con el mantenimiento de distintos y dispares planes de beneficios para zonas urbanas y trabajadores rurales, el hecho es que los inicios de un solo sistema de seguridad social surgió con la llegada del SINPAS, el cual simbolizó una nueva etapa: la cobertura universal de los programas de seguridad social en Brasil" (Beltrao et al. 2004: 24). En la era post-militar hubo una expansión y consolidación de este sistema con la creación en I990 del Instituto Nacional do Seguro Social (INSS), que reunió al INPS con el IAPAS. Para 20II, este sistema reunía a 64 millones de contribuyentes en una población de I90 millones de personas (IBGE, MPS 20II: 596).

El nuevo gobierno militar también creó en I966 el Fundo de Garantia por Tempo de Serviço, que se financiaba con un impuesto del $8 \%$ pagado por los empleadores. Este fondo podía ser utilizado como una suerte de seguro de desempleo para cualquier trabajador despedido -bajo las ahora mucho más flexibles formas de tenencia de mano de obra- o como un fondo de reserva para el trabajador por concepto de retiro o para adquirir una vivienda. En efecto, la mayoría de los dineros recogidos fueron al BNH para promover la construcción de casas (Malloy I979: I25-6) ningún plan. Bajo los gobiernos democráticos posteriores al período militar este monto se subió a un salario mínimo completo y las mujeres trabajadoras rurales también fueron incluidas.

${ }^{41}$ Para una discusión sobre estos cambios véase Beltrao et al. (2004: 19-49). 
Estos fondos fueron cruciales para el desarrollo de viviendas urbanas en un tiempo en que las ciudades de Brasil se expandían masivamente.

Desde el comienzo, las Caixas e Institutos habían dado asistencia médica a todos los miembros y sus familias, servicio que creció aún más rápido cuando se estableció el INPS. El auge de los seguros, de los hospitales públicos y privados, de las clínicas y la gran expansión del sistema de pensión/salud operado por el gobierno comenzó a alcanzar a partes significativas de la población brasileña. Entre I970 y ı980, los cotizantes en el sistema de Seguridad Social duplicaron su número aumentando del $9 \%$ al $20 \%$ de la población nacional, mientras que el 30\% de la población urbana estaba ahora cubierta. El INPS cubría inicialmente el seguro de salud de todos los cotizantes del sistema de Seguro Social, pero cuando en 1974 se creó el Ministério da Previdência e Assistência Social, estos distintos planes de seguros, de pensiones y de salud fueron puestos bajo una nueva organización dependiente del Ministerio. Este se llamó el Instituto Nacional de Assistência Médica e Previdência Social (INAMPS) y sería la principal agencia de salud del gobierno hasta el final de la era militar (Coutinho y Salm I989: 233-62). Una serie de otros cambios institucionales produjo una importante expansión del sistema de salud pública. Entre I970 y I980, la admisión hospitalaria subió de 6 a i3 millones, cifra que se mantiene actualmente (Paim et al. 20II: 5). Además, en los años sesenta se habían formado programas nacionales e internacionales de inmunización de infantes y niños, lo que se unió al desarrollo de un mercado de seguros privados completamente nuevo. ${ }^{42}$

Muchos de estos planes privados tuvieron su origen en las décadas de I940 y I950, y muy pronto se produjo una compleja mezcla entre públicos y privados, sobre todo relacionados con los hospitales fiscales. Por otro lado, a partir de I967 se organizaron grupos de cooperación médica (UNIMEDs), los cuales, para la década de I980, ofrecían el mayor numero de seguros privados en el mundo (Rabelais 200I: 999-1008).

Para fines de los años noventa se estimaba que 32 millones de brasileños estaban cubiertos por compañías privadas de seguros, haciendo de dicho mercado el segundo más grande del mundo (Bahia 20Iı: 329-

$4^{2}$ Las décadas de I970 y I980 fueron también un período en que se desarrolló un activo debate entre académicos y médicos sobre la naturaleza del sistema de salud, el cual tendría un profundo efecto en la creación del Sistema Único de Saúde (SUS) y en las reformas de descentralización llevadas a cabo en los años posteriores al régimen militar. Véase Cordeiro (2004: 343-62). 
39). En lo que concierne al final del período militar, a principios de I9 85 sólo un tercio de las instituciones de salud estaba en manos privadas, pero representaban dos tercios de las camas de hospitales y un poco menos de la mitad de los profesionales de la salud. Ahora bien, es importante señalar que en un sistema tan complejo como éste existía una constante superposición entre públicos y privados, con muchos hospitales recibiendo a ambos grupos sin importar que fueran instituciones públicas.

Este crecimiento público y privado de la seguridad en el ámbito de la salud tuvo un impacto directo en los índices de mortalidad. Para entonces, la tasa de mortalidad era de 15 muertes por cada mil habitantes. Aunque dicha tasa no cambiaría mayormente en la próxima década, aceleró su declinación en los años venideros y descendió a ocho muertes por mil habitantes para comienzos de los años I980. Este declive se explica porque la mortalidad infantil bajó a la mitad, desde 135 muertes por cada mil nacimientos en I950-I955 a sólo 63 en I980-I985. El impacto de este descenso puede verse en la lenta disminución de la mortalidad infantil y de niños (o-I4 años), la cuál disminuyó considerando el porcentaje total de muertes entre la población brasilera. Esta disminución comenzó a fines de la década de I970, cuando la mortalidad infantil y de niños (menores de I4 años) descendió de la mitad a sólo un tercio del total de muertes para principios de la década de I980.

Sin embargo, en esos años el fin del período del crecimiento 'milagroso' y la crisis internacional del petróleo tendrían un gran impacto en las finanzas públicas y especialmente en el sistema de seguridad social. Para 1994 el sistema estaba cerca de la bancarrota debido a la incorporación de los trabajadores que no pertenecían al servicio público. Esto crearía el trasfondo de la nueva reorganización democrática del Estado de Bienestar en la era post-militar, aun cuando estos cambios serían más evolutivos que revolucionarios. Los dos cambios más importantes, sobre todo después de la Constitución democrática de i988, fue un compromiso completo y efectivo con la universalidad de la atención de la salud para todos los brasileños y, para la década de I990 y la primera del siglo XXI, la universalización de las pensiones de jubilación. Incluyeron la creación de un Sistema Único de Saúde (SUS), junto con un nuevo estilo de traspaso de ingresos (bolsas familiares). Además, permitió que 
los empleados ingresaran al esquema nacional de pensiones. A pesar de que se introdujeron algunas reformas sustanciales en la administración del SUS mediante una significativa descentralización y del otorgamiento de concesiones a los municipios y a los Estados para ejercer el control sobre los hospitales, clínicas y otras áreas del sistema de salud financiado federalmente, no hubo un cambio relevante en el financiamiento de las pensiones. De hecho, en este período Brasil se diferenció de las reformas de pensiones más liberales llevadas a cabo en Latinoamérica, comenzando por Chile en los años ochenta y expandiéndose a muchos países de la región para la década siguiente. A diferencia de muchas otras naciones, Brasil no privatizó su esquema de pensiones sino que más bien solidificó y racionalizó su sistema de PAGY (pay as you go), cuestión que, en todo caso, no impidió que Brasil aceptara los planes de seguros privados suplementarios y el sistema privado de seguros de salud. ${ }^{43}$ Estas reformas puestas en práctica bajo el régimen democrático post-militar se hicieron con el fin de mejorar un sistema que funcionaba y que se había convertido en un elemento básico de la sociedad y el gobierno brasileños. Aun cuando los planes privados de salud y seguros crecieron en importancia en los años siguientes, hubo una expansión masiva de la cobertura financiada de forma pública a casi todos los trabajadores urbanos y rurales. Dicha expansión del sistema de bienestar social estatal, la disminución sistemática del mercado laboral informal y finalmente las transferencias de dinero fueron los factores centrales de la transformación de la pobreza de Brasil a principios del siglo XXI.

Así, a pesar de todos estos cambios y todas las críticas a las políticas de los gobiernos autoritarios con posteridad a I985, virtualmente todos los estudiosos concuerdan en que la estructura básica fundacional del Estado de Bienestar actual de Brasil fue elaborado tanto por el régimen de Vargas como por los gobiernos militares y que éste continúa intacto en la actualidad. Cualquiera hayan sido las motivaciones y el compromiso con las iniciativas públicas o privadas, como también con el poder de decisión centralizado o descentralizado, no existen dudas de que estos regímenes llevaron a Brasil hacia la universalización de la educación, de las pensiones y de la salud.

43 Para las diferencias comparativas de otras reformas regionales, véase Antía y Provasi (2011: 53-7I) y Betranou y Rofman (2002: 67-82). 
BIBLIOGRAFÍA

Abel, C., Lewis C.M. (eds) I993. Welfare, Poverty and Development in Latin America. London: Macmillan \& St. Antony's College.

Andrade, E.I.G. 2003. Estado e previdência no Brasil: Uma breve história. En Marques, R.M. (et al.), A previdência social no Brasil. São Paulo: Editora Fundação Perseu Abramo.

Antía, F. y Provasi, A. 20Ir. Multi-Pillared Social Insurance Systems: The PostReform Picture in Chile, Uruguay and Brazil. International Social Security Review 64(I), 53-7I.

Arretche, M.T.S. I999. Políticas sociais no Brasil: Descentralização em um Estado federativo. Revista Brasileira de Ciências Sociais I4(40), III-I4I.

Bacha, E. y Taylor, L. I980. Brazilian Income Distribution in the I96os: 'Facts', Model Results and the Controversy. En Taylor, L. (ed), Models of Growth and Distribution for Brazil. New York: Oxford University Press.

Bahia, L. 200I. Planos privados de saúde: Luzes e sombras no debate setorial dos anos 9o. Ciência a Saúde Coletiva 6(2), 329-339.

Barreto de Oliveira, F.E., Beltrao, K.I., y Guerra Ferreira, M. I997. Reforma da previdência. Rio de Janeiro, IPEA, Texto para Discussão 508.

Barreto de Oliveira, F.E., Beltrao, K.I., y de Albuquerque, A.C. I999. Dívida da União com a Previdência Social: Uma perspectiva histórica. Rio de Janeiro, IPEA, Texto para Discussão 638 .

Barreto de Oliveira, F.E. de Marsillac Pasinato, M.T., y Paes Leme Peyneau, F. 2000. Evolução recente do sistema de previdência complementar no Brasil e mercado potencial. [Online] Disponible en: http://www.abep.nepo. unicamp.br/docs/anais/pdf/2000/Todos/Evolu\%C3\%A7\%C3\%A30\%20 Recente\%2odo\%2oSistema\%2ode\%2oPrevid\%C3\%AAncia\%2o Complementar....pdf [20 de octubre 20I3].

Barroso Leite, C. I983. Da lei Elói Chaves ao Sinpas. En Barroso Leite, C. (ed), Um século de previdência social: Balanço e perspectivas no Brasil e no mundo. Rio de Janeiro: Jorge Zahar.

Batalha, C. 2000. O movimento Operário na Primeira República. Rio de Janeiro: Jorge Zahar.

Bello, E. 2007. Cidadania e direitos sociais no Brasil: Um enfoque político e social. Revista Espaço Jurídico 8(2), I33-I54. 
Bello, J.M. I976. História da República. São Paulo: Companhia Editora Nacional. Beltrão, K.I., Leme, F.P., Mendonça, J.L. y Sugahara, S. 2004. Análise da estrutura da previdência privada brasileira: Evolução do aparato legal. Rio de Janeiro, IPEA, Texto para Discussão I043.

Beltrão, K.I., Sugahara, S. y Barreto de Oliveira, F.E. 2004. Rural Population and Social Security in Brazil: An Analysis with Emphasis on Constitutional Changes. International Social Security Review 57(4), 19-49.

Betranou, F.M., Rofman, R. 2002. Providing Social Security in a Context of Change: Experience and Challenges in Latin America. International Social Security Review 55(I), 67-82.

Bonduki, N.G. I994. Origens da habitação social no Brasil. Análise Social 29(I27), 7II-732.

Bourn, R. I974. Getúlio Vargas of Brazil, 1883-1954: Sphinx of the Pampas. London: Knight.

Carone, E. I973. A segunda República. São Paulo: Difusão Européia do Livro.

Cohn, A. I98I. Previdência social e processo político no Brasil. São Paulo: Editora Moderna.

Cordeiro, H. 2004. Instituto de Medicina Social e a lutan pela reforma sanitária: Contribuição à história do SUS. Physis I4(2), 343-362.

Coutinho, M., y Salm, C. I989. Social Welfare. En Bacha, E.L. y Klein, H.S. (eds), Social Change in Brazil 1945-1985. The Incomplete Transformation. Albuquerque: University of New Mexico Press.

da Jornada, M.I. I989. A Política Salarial: Uma visão panorâmica da Legislação. Ensaios FEE I7(2).

de Castro, A. I988. A invenção do Trabalhismo. São Paulo: Vértice.

de Castro, A. 2000. O populismo e as ciencias sociais no Brasil: Notas sobre a trajetória de um conceito. En Ferreira, J. (ed), O populismo e sua história. Rio de Janeiro: Editora Civilização Brasileira.

de Souza, B. I983. Reforma administrativa da era de Vargas. Rio de Janeiro: Fundação Getúlio Vargas.

Diniz, E., y Camargo, A. I981. O Estado novo: Estrutura de poder e relações de classe. En Fausto, B. (ed), História Geral da Civilização Brasileira. Vol. ıo: Sociedade e política (1930-I964). Tomo III. São Paulo: Difel.

do Valle, C. 2oII. Um estado de bem-estar social no Brasil? MA Thesis, Universidade Federal Fluminense. 
dos Santos, R.D. 2007. Francisco Campos e os fundamentos do constitucionalismo antiliberal no Brasil. DADOS, Revista de Ciências Sociais 50(2), 28I-323.

Draibe, S. I993. O Welfare State in Brazil: Caracteristicas e perspectivas. UNICAMP, NEPP, Caderno de Pesquisa 8.

Draibe, S. 2002. The National Social Policies System in Brazil, Construction and Reform. UNICAMP, NEPP, Caderno de Pesquisa $5 \mathrm{I}$.

Dulles, J.W.F. I967. Vargas of Brazil: A Political Biography. Austin: Universtiy of Texas Press.

Esping-Andersen, G. I990. The Three Worlds of Welfare Capitalism. Princeton N.J.: Princeton University Press.

Faria, L. 2007. Saúde e Política: A Fundação Rockefeller e seus parceiros em São Paulo. Rio de Janeiro: Editora Fiocruz.

Fausto, B. 1972. A Revolução de 1930. Brasil: Editôra Brasiliense.

Fausto, B. 1997. Trabalho urbano e conflito social. São Paulo: DIFEL.

Fausto, B. 200I. O pensamento nacionalista autoritário. Rio de Janeiro: Jorge Zahar.

Fausto, B. 2ого. Populismo in the past and its resurgence. Work presented in the Conference in Honor of Boris Fausto, Stanford.

Fernandes, P. 2007. Setenta anos após I937: Francisco Campos, o Estado Novo e o pensamento jurídico autoritário. Prisma Jurídico 6, 35I-370.

Ferreira, J. 2000. O nome e as coisas: O populismo na política brasileira. En Ferreira, J. (ed), O populismo e sua história. Rio de Janeiro: Editora Civilização Brasileira.

Fishlow, A. I972. Brazilian Size Distribution of Income. American Economic Review 2(62), 39I-402.

French, J.D. 2006. Proclamando leis, metendo o pau e lutando por direitos. En Hunold Lara, S. y Nunes Mendonça, J.L (eds), Direitos e Justiças no Brasil, Ensaios de História Social. Campinas: Editora Unicamp.

Garcia, N.R. 20I0. Prorural: Uma política previdenciária para o campo no governo Medici (1969-1973). MA Thesis. Rio de Janeiro: Editora Fiocruz.

Giannotti, V. 2007. Historia das lutas dos trabalhadores no Brasil. Rio de Janeiro: Mauad X.

Lamounier, B. I985. O 'Brasil autoritário’ revisitado: O impacto das eleições sobre a ditadura. En Stepan, A. (ed), Democratizando o Brasil. Rio de Janeiro: Paz e Terra.

Langoni, C.G. I973. Distribuição de renda e desenvolvimento econômico no Brasil. Rio 
de Janeiro: Expressão e Cultura.

Levine, R.M. I998. Father of the Poor? Vargas and his Era. Cambridge: Cambridge University Press.

Linz, J. I976. The Future of an Authoritarian Situation or the Institutionalization of an Authoritarian Regime: The Case of Brazil. En Stepan, A. (ed), Authoritarian Brazil. New Haven: Yale University Press.

Loewenstein, K. I942. Brazil under Vargas. New York: The Macmillian Company. Malloy, J. I979. The Politics of Social Security in Brazil. Pittsburgh: University of Pittsburgh Press.

Martins, C.B. 2000. O ensino superior brasileiro nos anos 90. São Paulo em Perspectiva I4(I), 4I-60.

Merrick, T. y Graham, D. I979. Population and Economic Development in Brazil, 1800 to the Present. Baltimore: Johns Hopkins University Press.

Mesa-Lago, C. I977. Modelos de seguridad social en América Latina. Estudio comparativo. Buenos Aires: Ediciones Siap-Planteos.

Miceli, S. I979. Intelectuais e classe dirigente no Brasil (1920-1945). São Paulo: Difel. Morreira Alves, M.H. I984. Estado e oposição no Brasil, 1964-1984. Petrópolis: Vozes.

Neto, L. 20I2. Getúlio 1882-1930. Dos anos de formação à conquista do poder. São Paulo: Cia. das Letras.

Oliveira, J. y Fleury, S. 1986. (Im)previdência Social: 6o Anos de História da Previdência no Brasil. Petrópolis: Associação Brasileira Pós-Graduação em Saúde Coletiva. [Online] Disponible en: http://www.scribd.com/ doc/92369057/Decreto-4682-24janeirol923-Lei-Eloy-Chaves- Cap [20 de octubre 2013].

Oliveira Fonseca, C.M. I993. A Saúde da Criança na Política Social do Primeiro Governo Vargas. PHYSIS - Revista de Saúde Coletiva 3(2), 97-ıі6.

Oliveira Fonseca, C.M. 2007. Saúde no Governo Vargas (1930-1945): Dualidade institucional de um bem público. Rio de Janeiro: Editora Fiocruz.

Paim, J., Travassos, C., Almeida, C., Bahia, L., y Macinko, J. 20II. The Brazilian Health System: History, Advances, and Challenges. The Lancet 377(9779), I778-I797.

Quine, M.S. 2002. Italy's Social Revolution: Charity and Welfare From Liberalism to Fascism. New York: Palgrave.

Rabelais Duarte, M.C. 200I. UNIMED: História e características da cooperativa de trabalho médico no Brasil. Cadernos de Saúde Pública I7(4), 999-Ioo8. 
Ramos, L.R.A, y Almeida, J.G. 2000. Distribuição da renda: Aspectos teóricos e o debate no Brasil. En Camargo, J.M., Giambiagi, F. (eds), Distribuição de renda no Brasil. Rio de Janeiro: Paz e Terra.

Ribeiro, C.A. 2003. Estrutura de classe e mobilidade social no Brasil. São Paulo: EDUSC.

Saboia, J. I990. Salário e produtividade na indústria brasileira: Os efeitos da política salarial no longo prazo. Pesquisa e Planejamento Econômico 20(3), 58I-599.

Saboia, J. 2000. Política Salarial e distribuição de renda: 25 anos de desencontros. En Camargo, J.M. y Giambiagi, F. (eds), Distribuição de renda no Brasil. Rio de Janeiro: Paz e Terra.

Schmitter, P.C. I976. The 'Portugalization' of Brazil. En Stepan, A. (ed), Authoritarian Brazil. New Haven: Yale University Press.

Schwartzman, S., Bomeny, H.M.B. y Costa, V.M.R. I984. Nos tempo de Capanema. São Paulo: Editora da Universidade de São Paulo e Ed. Paz e Terra.

Schwartzman, S. I991. A Space for Science - The Development of the Scientific Community in Brazil. College Park: Pennsylvania State University Press.

Segura-Ubiergo, A. 2007. The Political Economy of the Welfare State in Latin America: Globalization, Democracy, and Development. Cambridge: Cambridge University Press.

Simonsen, M.H. I970. Inflação: Gradualismo $x$ Tratamento de Choque. Rio de Janeiro : Apec Editôra.

Skidmore, T.E. I973. Politics and Economic Policy Making in Authoritarian Brazil, I937- I97I. En Stepan, A. (ed), Authoritarian Brazil. New Haven: Yale University Press.

Skidmore, T.E. 1976. Politics in Brazil, 1930-1964. Oxford University Press: New York.

Skidmore, T.E. 1988. The Politics of Military Rule in Brazil, 1964-85. New York: Oxford University Press.

Skidmore, T.E. 2007. Politics in Brazil, 1930-1964: An Experiment in Democracy. Oxford: Oxford University Press.

Sola, L. I969. O golpe de 37 e o Estado Novo. En Guilherme Mota, C.G. (ed), Brasil em perspectiva. São Paulo, Difusão Européia do Livro.

Spalding, R.J. I980. Welfare Policymaking: Theoretical Implications of a Mexican Case Study. Comparative Politics I2(4), 4I9-438. 
Stepan, A. 1985. As prerrogativas militares nos regimes pósautoritários: Brasil, Argentina, Uruguai e Espanha. En Stepan, A. (ed), Democratizando o Brasil. Rio de Janeiro: Paz e Terra.

Todaro, M. I974. Integralism and the Brazilian Catholic Church. Hispanic American Historical Review 54(3), 43I-452.

Vargas, G. I943. As diretrizes da nova política do Brasil. Rio de Janeiro: José Olympio Editora.

Vidal Luna, F. y Klein, H.S. 2006. Brazil Since 1980. New York \& Cambridge: Cambridge University Press.

Vidal Luna, F. y Klein, H.S. 2013. An Economic and Social History of Brazil Since 1889. New York \& Cambridge: Cambridge University Press.

Vieira de Campos, A.L. 2006. Políticas internacionais de saúde na era Vargas: O Serviço Especial de Saúde Pública, 1942-196o. Rio de Janeiro: Editora Fiocruz.

Weffort, F. I980. O populismo na política brasileira. Rio de Janeiro: Paz e Terra.

Weinstein, B. I990. The Industrialists, the State, and the Issues of Worker Training and Social Services in Brazil, I930-50. Hispanic American Historical Review 70(3), 379-404.

Weinstein, B. I996. For Social Peace in Brazil: Industrialists and the Remaking of the Working Class in São Paulo, 1920-1964. Chapel Hill, N.C.: University of North Carolina Press.

Zahluth, P. y Dutra, P. (eds) 2012. A Era Vargas. Desenvolvimento, economia e sociadade. São Paulo, Editora Unesp.

Zamagni, V. (ed) 2000. Povertà e innovazioni istituzionali in Italia. Bologna: Il Mulino.

FUENTES

ABRAPP, ICSS, SINDAPP. Fundamentos da Previdência Complementar, Ensino a distância. [Online] Disponible en: http://www.fbss.org.br/dados/wwwfbs/ publica\% $\mathrm{C}_{3} \% \mathrm{~A}_{7} \% \mathrm{C}_{3} \% \mathrm{~B}_{5}$ es\%2 ot\%C3\%A9cnicas/Fundamentos\%2o da\%2oPrevid\%C3\%AAncia\%2oComplementar.pdf [io de octubre de 2013].

BNDES. Privatizações no Brasil I99I-2002. [Online] Disponible en: http:// www.bndes.gov.br/SiteBNDES/export/sites/default/bndes_pt/Galerias/ Arquivos/conhecimento/especial/Priv_Gov.PDF [1o de octubre de 2013]. 
IBGE. Anuário Estatístico do Brasil (aeb). [Online] Disponible en: http://biblioteca. ibge.gov.br/d_detalhes.php?id=720 [10 de octubre de 20I3].

IBGE. Anuário Estatístico da Previdência Social (MPS). [Online] Disponible en: http://www.previdencia.gov.br/arquivos/office/I_I21023-162858-947.pdf [Io de octubre de 20I3].

IBGE. Estatística do Século XX. [Online] Disponible en: http://seculoxx.ibge.gov. br/es/publicacao [Io de octubre de 20I3].

Recibido octubre 2013

Aceptado enero 2014

Traducción Juan Luis Ossa Santa Cruz 
